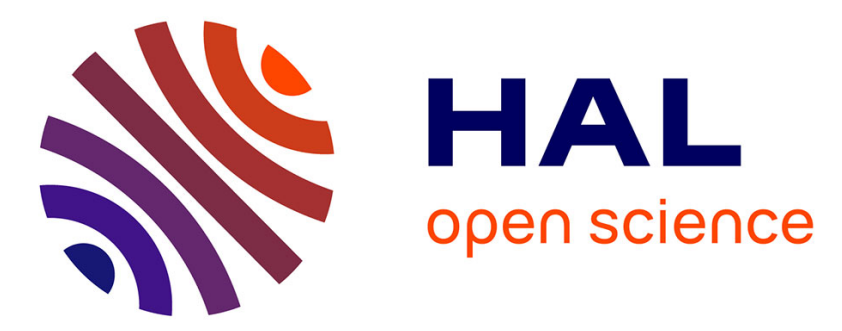

\title{
Solar energy potential atlas for planning energy system off-grid electrification in the Republic of Djibouti
}

Benjamin Pillot, Marc Muselli, Philippe Poggi, Pierrick Haurant, Idriss Hared

\section{To cite this version:}

Benjamin Pillot, Marc Muselli, Philippe Poggi, Pierrick Haurant, Idriss Hared. Solar energy potential atlas for planning energy system off-grid electrification in the Republic of Djibouti. Energy Conversion and Management, 2013, 69, pp.131-147. 10.1016/j.enconman.2013.01.035 . hal-00801449

\section{HAL Id: hal-00801449 \\ https://hal.science/hal-00801449}

Submitted on 18 Mar 2013

HAL is a multi-disciplinary open access archive for the deposit and dissemination of scientific research documents, whether they are published or not. The documents may come from teaching and research institutions in France or abroad, or from public or private research centers.
L'archive ouverte pluridisciplinaire HAL, est destinée au dépôt et à la diffusion de documents scientifiques de niveau recherche, publiés ou non, émanant des établissements d'enseignement et de recherche français ou étrangers, des laboratoires publics ou privés. 
Solar energy potential atlas for planning energy system off-grid electrification in the Republic of Djibouti

Benjamin Pillot ${ }^{1}$, Marc Muselli ${ }^{1 \star}$, Philippe Poggi ${ }^{1}$, Pierrick Haurant ${ }^{1}$, Idriss Hared $^{2}$

${ }^{1}$ Université de Corse, UMR CNRS 6134 SPE, Route des Sanguinaires, 20000 Ajaccio, France; Email:

pillot@univ-corse.fr; marc.muselli@univ-corse.fr; philippe.poggi@univ-corse.fr; haurant@univ-corse.fr

${ }^{2}$ Centre d'Etudes et de Recherche de Djibouti, Route de l'aéroport, B.P. 486 Djibouti, République de Djibouti

Email: ihared1@yahoo.fr

•Corresponding author; Email: marc.muselli@univ-corse.fr, Tel.: +33 (0)4 9552 41 30; fax: +33 (0)4 9545 3328

Paper length: 9475 words (including introduction, main text and conclusion)

\begin{abstract}
Nowadays, energy supply of rural populations is one of the most important challenges in African developing countries, and more particularly in Sub-Saharan Africa. With only one third of the population connected to the grid and the high economical and environmental cost of classical energy resources, the use of renewable energies within the rural energy supply pattern is a reliable alternative solution to improve human
\end{abstract}


development of remote populations. Djibouti is a little poor country of Sub-Saharan Africa which perfectly symbolizes this way of life. Electrification rate is only about $30 \%$ and the important scattering of rural peoples throughout the country makes grid extension and fuel transportation unsuitable economic solutions to carry energy. The geographically diffused solar resource can therefore be an interesting mean to produce energy where it is consumed.

The aim of this study was the creation of the first Djibouti's global horizontal irradiation atlas, including assessment and improvement. To realize this atlas, a satellite-derived irradiance model was used (EUMETSAT O\&SI SAF). To validate this model over Djibouti, we installed 2 temporary weather stations during the year 2010 in Djibouti-city and Dikhil and we compared hourly, daily and monthly irradiation estimates against ground-based measurements. Results showed a good agreement between measures and estimates, with a maximum Relative Root Mean Squared Error (RRMSE) over the hourly solar atlas of $12.43 \%$ and $15.44 \%$, for Dikhil and Djibouti-city respectively.

In order to improve geographic information and accuracy of this solar atlas, we then disaggregated irradiation maps with a 3 arc second ( 90 meters at the equator) Digital Elevation Model (DEM), by taking into consideration terrain-related shading effects and elevation gradient. As current software solutions don't allow downscaling of preprocessed maps, we performed this work by computing our own global model, combination of horizon, elevation correction and irradiance splitting models. The horizon model we developed was assessed and compared with other existing models by using a theodolite in mountainous areas of Corsica.

Finally, according to the final computed atlas, during the year 2010, mean irradiation all over the country was around $2100 \mathrm{kWh} / \mathrm{m}^{2}$ and about $82 \%$ of the country received over $2000 \mathrm{kWh} / \mathrm{m}^{2}$. Furthermore, the solar radiation reaching Djibouti corresponded to 20000 times the total yearly energy consumption of the country in 2005. The retrieved irradiation maps can be used to evaluate relevance of the solar resource over rural areas of the country, and implemented within energy models in order to size stand-alone solar systems.

Keywords: Africa, Disaggregation, Djibouti, Energy planning, Off-grid electrification, Ground measurements, Satellite-based solar atlas 


\section{Nomenclatures}

A Top of Atmosphere (TOA) albedo

B narrowband to broadband conversion coefficient

C radiometer count

$c_{\text {offset }} \quad$ calibration offset of SEVIRI level 1.5 header $\left(\mathrm{mW} \mathrm{m}^{-2} \mathrm{sr}^{-1}\left(\mathrm{~cm}^{-1}\right)^{-1}\right)$

cal $_{\text {slope }} \quad$ calibration slope of SEVIRI level 1.5 header $\left(\mathrm{mW} \mathrm{m}^{-2} \mathrm{sr}^{-1}\left(\mathrm{~cm}^{-1}\right)^{-1}\right)$

$d_{k} \quad$ calculated distance from observer point to the horizon $\mathrm{k}$ point (m)

$E_{0} \quad$ solar constant $\left(1358.2 \mathrm{~W} / \mathrm{m}^{2}\right)$

$f \quad$ radiance to reflectance factor $\left(21.21 \mathrm{~mW} \mathrm{~m}^{-2} \mathrm{sr}^{-1}\left(\mathrm{~cm}^{-1}\right)^{-1}\right)$

$f_{\text {aniso }} \quad$ anisotropic factor or Bi-directional Reflectance Distribution Function (BRDF)

$G_{0} \quad$ global horizontal extraterrestrial irradiance $\left(\mathrm{W} / \mathrm{m}^{2}\right)$

$G_{h} \quad$ global horizontal irradiance $\left(\mathrm{W} / \mathrm{m}^{2}\right)$

$G_{h, \text { shading }}(z)$ DEM-based global horizontal irradiance, taking into account shadowing effects $\left(\mathrm{W} / \mathrm{m}^{2}\right)$

$I_{i} \quad$ ith measured global horizontal irradiation value $\left(\mathrm{Wh} / \mathrm{m}^{2}\right)$

$\bar{I} \quad$ measured global horizontal irradiation mean value $\left(\mathrm{Wh} / \mathrm{m}^{2}\right)$

$I_{i}^{\prime} \quad$ ith estimated global horizontal irradiation value $\left(\mathrm{Wh} / \mathrm{m}^{2}\right)$

$\overline{I^{\prime}} \quad$ estimated global horizontal irradiation mean value $\left(\mathrm{Wh} / \mathrm{m}^{2}\right)$

$I_{h, \text { shading }}(z) \quad$ DEM-based global horizontal irradiation, taking into account shadowing effects $\left(\mathrm{Wh} / \mathrm{m}^{2}\right)$

j day of the year

$k_{d} \quad$ diffuse fraction

$k_{t} \quad$ clearness index

$L_{S C} \quad$ scaled radiance (unitless)

M narrowband to broadband conversion coefficient 
$p \quad$ vertices on the hemisphere

broadband reflectance (unitless)

$R_{D E M} \quad$ local average DEM resolution (m)

$R_{n b} \quad$ narrowband reflectance (unitless)

$S_{b} \quad$ direct shading factor

$S_{d, h} \quad$ isotropic horizontal diffuse shading factor

$S_{\text {horizon }} \quad$ average error sensitivity coefficient

$T_{1} \quad$ sun-surface atmospheric transmittance (unitless)

$T_{a} \quad$ clear sky atmospheric transmittance (unitless)

$T_{c l} \quad$ cloud factor (unitless)

$z \quad$ DEM elevation (m)

$z_{0} \quad$ mean GTOPO30 elevation (m)

$\alpha \quad$ horizon elevation angle (rad)

$\alpha_{k} \quad$ horizon elevation angle of the k point (deg)

$\alpha_{H}^{\gamma_{S}} \quad$ horizon elevation angle in the sun azimuth angle direction (rad)

$\alpha_{S}^{\gamma_{S}} \quad$ sun elevation angle in the sun azimuth angle direction (rad)

$\gamma \quad$ horizon azimuth angle (rad)

$\gamma_{S} \quad$ sun azimuth angle (rad)

$\theta_{0} \quad$ sun zenith angle (rad)

$v(j) \quad$ corrective term describing Earth-sun distance seasonal variation (unitless)

$\tau(z) \quad$ optical thickness of the atmosphere

\section{List of acronyms}


$\mathrm{CC}$

CERD

CGIAR-CSI

DEM

EUMETSAT

GIS

GTOPO30

HDI

MBE

MSG

O\&SI SAF

RMBE

RMSE

RRMSE

SEVIRI

SRTM

SRTM-1

SRTM-3

SSI

UTC
Correlation Coefficient

Centre d'Etudes et de Recherche de Djibouti

Consultative Group for International Agriculture Research Consortium for Spatial Information

Digital Elevation Model

European Organisation for the Exploitation of Meteorological Satellites

Geographical Information System

Global 30 Arc Second Elevation Data

Human Development Index

Mean Bias Error

Meteosat Second Generation

Ocean and Sea Ice Satellite Application Facility

Relative Mean Bias Error

Root Mean Squared Error

Relative Root Mean Squared Error

Spinning Enhanced Visible and Infrared Imager

Shuttle Radar Topography Mission

SRTM data at 1 arc second resolution

SRTM data at 3 arc second resolution

Surface Solar Irradiance

Coordinated Universal Time

\section{Introduction}

Nowadays, energy supply of rural populations is one of the most important challenges in African developing countries, and more particularly in Sub-Saharan Africa. Thus, about 68\% of inhabitants in Sub-Saharan 
Africa are living in rural areas when electrification rate of these populations is usually below 5\% [1].

Furthermore, as many recurrent power supply utility crisis have occurred in African nations over the past years [2], these countries have to foremost stabilize their existing electrical grid, while expand the network in order to reach small and dispatched stand alone areas presents apparent economic limitations [1]. Finally, at the same time, classical stand alone energy supply solutions present important restrictions. Indeed, oil price was constantly increasing for several years [2] and the massive use of remote resources, as fuel-wood, often destroys environment dramatically and causes severe socio-economic troubles [3]. Obviously, this specific energy supply layout has dramatic consequences. As these remote populations can't get out of the poverty without any difficulties, most of them end up moving around urban centers, crowding with other rural migrants into suburban shantytowns. As a result of this background, African governments were looking for alternative power systems. Among them, renewable energies present a reliable profile for an economical and sustainable development, especially for rural and stand alone populations [1-4]. As Africa presents important renewable resources [3], integration of these energies is part of the main policies across the continent $[2,5]$.

The Republic of Djibouti is a little developing country located in the Horn of Africa which perfectly symbolizes the energy challenge in Sub-Saharan Africa. Low electrification rate, instability of the existing centralized electrical network, fuel cost or lack of fossil resources make energy as one of the first government's priorities. Like other African governments, the use of renewable energies is more and more taken into consideration within the energy policy of the country [6]. If the country presents high geothermal and solar potentials a priori [6], the geographically diffused solar resource probably represents the best way to improve human development and reduce poverty of Djiboutian rural peoples. That's why this article will focus on this specific renewable resource.

The use of solar resource through future solar systems requires exactly knowing it and its geographical distribution over the country, in order to evaluate relevance of the solar solution for each remote area. That is, as no solar study has ever been realized in the country, to develop a solar atlas. At the moment, Africa's solar mapping remains complicated, especially due to the lack of long timeseries ground data [7]. Some solar potential studies exist about Sub-Saharan Africa [8-10] but still present limited subsequent 
applications. In Djibouti, no solar mapping study has been yet achieved because of the lack of ground solar data [6]. Nevertheless, many models have been developed in order to derive irradiance from instantaneous satellite images. From a strictly science point of view, for a solar mapping process, satellite-based irradiance data are more accurate than an interpolation of ground data $[11,12]$. From logistics consideration, satellite data are essential in a country like Djibouti, where any pyranometer and meteorological networks don't exist [6] and where cost, maintenance or material safety are important restrictions to a modern temporary meteorological network deployment.

Therefore, in this work, we used the Surface Solar Irradiance algorithm (SSI), an hourly satellite-based irradiance model developed by the European Organisation for the Exploitation of Meteorological Satellites (EUMETSAT) Ocean and Sea Ice Satellite Application Facility (O\&SI SAF). The aim of this study was the creation of the first Djibouti's solar energy atlas of global horizontal irradiation and one of the main upcoming objectives, to size PV systems [13] and other solar systems across the country. So, the better time and spatial resolutions of solar maps are, the more accurate the solar system sizing will be. The temporal resolution of the solar atlas was predetermined by the irradiance model hourly time step. Then, according to Ruiz-Arias et al. [14] and Bosch et al. [15], it was possible to improve irradiance accuracy and spatial resolution by using a Digital Elevation Model (DEM) in order to take into account the topography effects. Hence, we developed a disaggregation methodology, including development and assessment of a new fast horizon algorithm, in order to produce the first downscaled hourly irradiation atlas of the Republic of Djibouti.

This paper is divided into three main parts. Since developing and developed countries present different social and energy paradigms, the first part features relevance of this research within the off-grid electrification pattern. Secondly, the solar computation quality assessment is presented, by comparing estimated data against ground data measured by temporary weather stations deployed during the year 2010 , in collaboration with the "Centre d'Etudes et de Recherche de Djibouti" (CERD), the national Djiboutian Science laboratory. Finally, the disaggregation methodology is presented, and results of the whole disaggregated solar mapping computation are, finally, exposed. 
2. The off-grid electrification paradigm: a mean to reduce poverty in developing countries

\subsection{Electricity and development}

Without any doubt, the advent of the electricity at the end of the nineteenth century has changed "the face of the Earth [...] forever" [16]. If energy consumption per capita has increased over the centuries with the technology developed to simplify everyday productive activities, modern life was made possible by the discovery of electrical phenomena, the development of alternating current for carrying electricity over long distances and, so, the emergence of a "clean" and easy to use energy in day to day life of world populations. Not only the development of electric lighting, modern media and communication or devices getting daily comfort better but also the quality improvement of many basic services such as medical care, education or clean water was achieved by the use of electrical energy.



Figure 1: Human Development Index vs. per capita electricity use [17].

Human development, and so quality of life, comes with electrification. This fact can be observed within Figure 1 which describes the close correlation existing between electricity consumption and the Human Development Index (HDI) [17], an index measuring quality of life and calculated by the United Nations Development Programme (UNDP) on the basis of life expectancy, education and Gross National Income (GNI) [18].

2.2. Developed countries vs. developing countries: two different social and energy patterns 
If electricity can ensure development and improve quality of life, electrification of most developing countries should be significantly different from electrification of developed countries, since different social and energy paradigms occur.

Hence, in 2005, the electrification rate of developed countries was equal to $99.5 \%$ against $68.3 \%$ for developing countries [19]. At the same time, urbanization rate of the more developed regions in the world was $74.4 \%$ and $43.8 \%$ for the less developed regions [20]. By relating these social and energy paradigms, we can finally observe that about $80 \%$ of the peoples without access to electricity in the world live in rural areas. In particular, Sub-Saharan Africa stays the least electrified region in the world with only $26 \%$ of the population with access to electricity. And, with 438 billion peoples, the rural electrification rate of SubSaharan developing countries is about only $8 \%$ while it equals to $61.7 \%$ for the rest of the world [19]. This specific layout requires a change in the electrification approach. While populations of developed countries are mainly concentrated in urban areas, Sub-Saharan peoples are scattered across the continent within little rural areas [1]. Thus, the centralized power distribution system of industrialized countries [21] doesn't seem really suitable anymore in this context. Indeed, on the one hand, the wide diffusion of rural populations across the considered territory would necessitate a highly meshed electrical network and a lot of power converter systems. On the other hand, the great distance between rural regions, and between rural and urban areas, would require an extensive transmission network for transporting electricity toward sparsely populated and possibly hardly accessible areas. These considerations show how this kind of network wouldn't be, a priori, economically viable [4]. Furthermore, at present time, with a still low $58.3 \%$ urban electrification rate [19] and persistent decline of their existing centralized network [2], many Sub-Saharan countries have to firstly stabilize their existing electrical grid before connecting rural areas, increasing thereby the state of abandonment of these populations and the necessity to find alternatives.

Therefore, rather than extending existing electrical grids and carrying electricity through broad transmission and distribution systems of a centralized network, electricity can be produced in the place where it is consumed. This is the off-grid electrification pattern [16]. 


\subsection{Renewable energies within the off-grid electrification pattern}

In rural areas, the density of populations and the intensity of electricity use are not as large as in the cities or in the industrial centers [16]. So, off-grid electrification doesn't require large-scale power systems. At present time, Sub-Saharan remote populations mostly use firewood as fuel and diesel generator as electric power supply $[3,16]$. However, the massive use of fuel-wood is frequently the source of severe socioeconomic troubles [3] and the service of fuel generators is restricted by the increasing cost of operation and equipment maintenance $[2,16]$. It is therefore necessary to look for other economic and energetic alternatives.

Renewable energies are mainly small-scale power systems. This small size is well adapted to the off-grid electrification or rural energy supply patterns, ensuring flexibility and speed of construction [3]. The other big advantage is that one or more renewable resources are still recoverable at the place where rural populations live. Indeed, if electrical grid requires extension and fossil resources necessitate transportation to the location where energy will be consumed, the geographical dispersion of renewable energies, even though it reduces their power capacity, increases their accessibility, especially for rural peoples. Hence, if renewable energies mainly represent environmental and resource alternatives in developed countries, they are above all a reliable economic alternative to the use of classical energy resources and power systems in developing countries.

\subsection{The case of Djibouti}

Located in the Horn of Africa, the Republic of Djibouti is a $23200 \mathrm{~km}^{2}$ little Sub-Saharan country of about 900000 inhabitants [18]. The population is mostly urban with $76.3 \%$ of peoples living in cities and $65 \%$ for only the capital $[6,18]$. With an HDI value of 0.43 and an HDI rank of 165, Djibouti is part of the lowest developing countries in the world [18].

In 2003 , the production of electricity was around $270 \mathrm{GWh}$ and the total power of the electrical grid is, at present time, about $130 \mathrm{MW}$. The available power of the fuel power plants forming the centralized network 
was only about $60 \%$ in 2007 and only $30 \%$ of the population has access to electricity for now [6]. Figure 2 presents electrical grid and geographical repartition of the population throughout the country. With regard to the $23.7 \%$ rural rate, electrical grid instability and low electrification rate, we can observe that the geographical scattering of low populated rural villages doesn't justify extension of the centralized network and requires an off-grid approach. Moreover, we can also note that the slightly extended modern road network limits accessibility of remote populations, which can therefore increase cost of fuel transportation and so fuel operations like, for instance, diesel power generation.

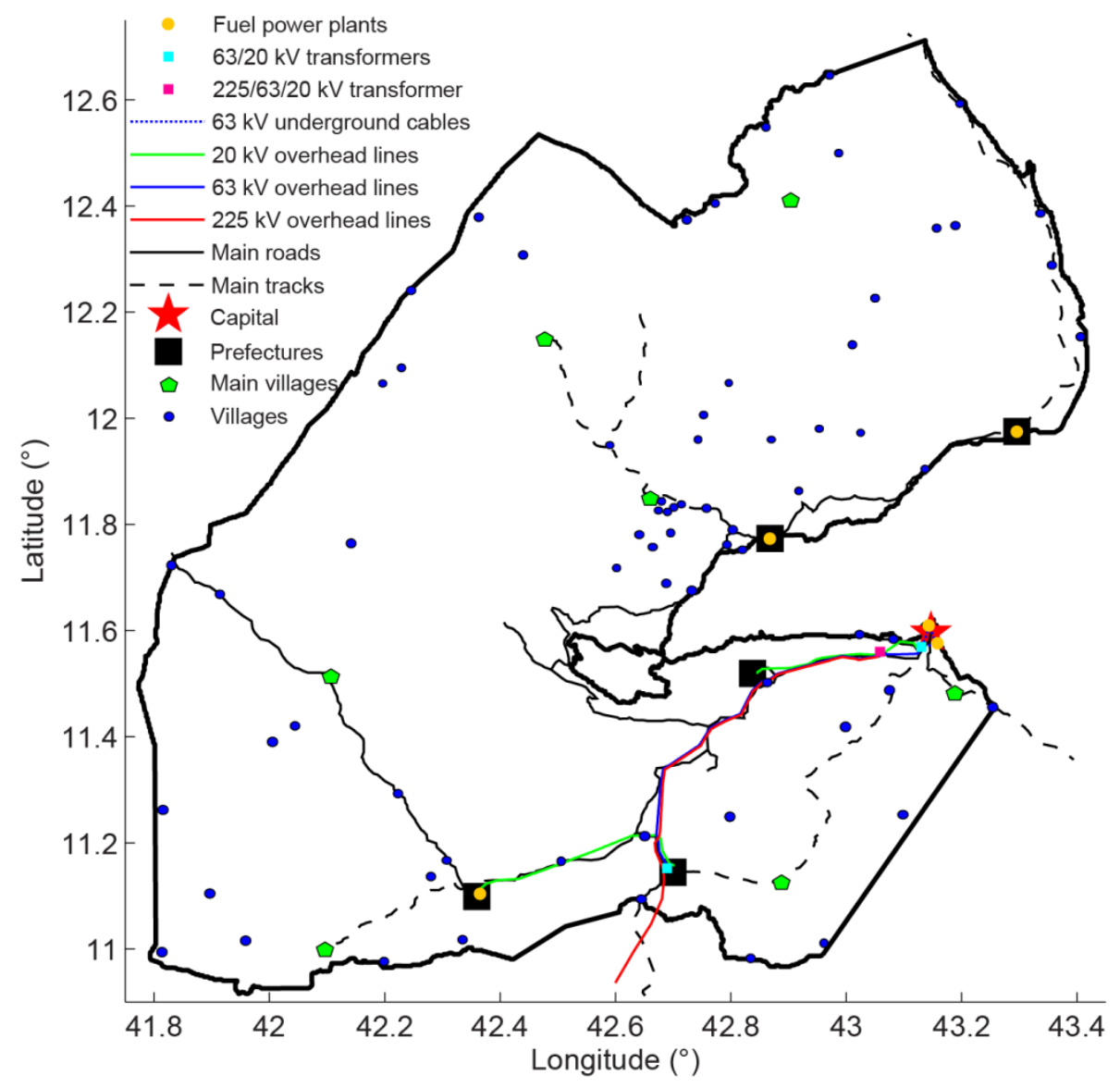

Figure 2 : Electrical grid of Djibouti and population repartition throughout the country.

Energy is one of the main purposes of the Djiboutian government's policy. Like other African countries, a large part of this energy policy includes the use of renewable energies. However, their integration within the energy scheme stays low at the moment, although great geothermal and solar potential are existing [6]. If geothermal energy should permit an important centralized production of electricity in the future, the scattered solar resource could be used within the off-grid electrification paradigm, as, for instance, photovoltaic electrification, including Solar Home Systems (SHS) [22], solar thermal electrification [23] or Concentrated Solar Power (CSP) [24,25]. Furthermore, as the very sparsely vegetation coverage of the 
country $(\sim 3.2 \%)$ restrains fuel supply for rural populations and some day to day productive activities can also be "modernly" and safely achieved without electricity, the off-grid pattern can be included in the larger rural energy supply pattern. As an example, solar cooking seems to be also a interesting alternative to the use of fuel and fuel-wood [6,26,27].

Consequently, in order to evaluate relevance of the solar energy solution and plan integration of future solar systems into rural energy scheme of Djibouti, it was necessary to estimate solar radiation reaching the country, i.e. to develop a solar atlas. The following part focuses on the use of the O\&SI SAF SSI satellitederived model to achieve this step.

\section{Quality assessment of the O\&SI SAF satellite-based irradiance model over Djibouti}

\subsection{The Surface Solar Irradiance algorithm}

\subsubsection{The Ocean \& Sea Ice Satellite Application Facility and MSG-2 satellite}

The EUMETSAT has created a Satellite Application Facilities (SAF) network to take benefits from specialized scientific expertise at national meteorological institutes across the member states in Europe. SAF are based on cooperation between several institutes and hosted by a National Meteorological Service. The EUMETSAT O\&SI SAF was created in 1997 and is hosted by Météo-France. It is specialized in both production and distribution of satellite-derived products, characterizing the ocean surface and radiative fluxes over the sea surface $[28,29]$. It distributes the Surface Solar Irradiance product (SSI) retrieved, at present time, by the MSG-2/Meteosat 9 satellite located over the equator at $0^{\circ}$ longitude. The continuous observation of the Earth disk is achieved by the main instrument boarded on the satellite, the 12-channel Spinning Enhanced Visible and Infrared Imager (SEVIRI) imaging radiometer [30,31].

\subsubsection{Description of the O\&SI SAF SSI processing scheme}


The SSI algorithm is a physical model developed by the EUMETSAT O\&SI SAF [32,33], which has been controlled and validated against in situ data in many places around the world [34,35] and which is fully described in a product manual intended for users [36]. The data production processing scheme is completely operational since July 2004 and SSI products are available through the Meteo-France server, ftp.meteo.fr. Thus, as a large documentation dataset already exists, we are just going to explain the basic statements of the model.

The SSI algorithm is a physical parameterization which, applied to every pixel of a satellite image, produce instantaneous fields of the global horizontal solar radiation $\left(\mathrm{W} / \mathrm{m}^{2}\right)$ reaching the Earth in the band 0.3-4 $\mu \mathrm{m}$. SSI products corresponding to our study area have a 0.1 degree spatial resolution in longitude and latitude and are called hourly SSI because of the MSG image process time sampling.

The SSI model combines a main processing scheme using the satellite visible channel input, and different auxiliary parameters (fixed atlas, monthly climatology and instantaneous fields). It can be summarized as follow:

- Re-mapping of the MSG-2 satellite image, at satellite resolution, onto the $0.1^{\circ} \mathrm{SSI}$ grid.

- Calibration of the SEVIRI 0.6 $\mu \mathrm{m}$ visible channel (Conversion of the satellite visible count into a bidirectional reflectance):

$$
\begin{aligned}
& L_{S C}=\left(\text { cal }_{\text {offset }}+\text { cal }_{\text {slope }} C\right) / f \\
& v(j)=1+0.0334 \cos [2 \pi(j-2) / 365.25] \\
& R_{n b}=L_{S C} /\left[v(j) \cos \theta_{0}\right]
\end{aligned}
$$

Within the Rogers and Pili calibration equation (1) [37], the scaled radiance $L_{S C}$ corresponds to the radiance, measured by SEVIRI, divided by the top of atmosphere effective solar irradiance, i.e. the top of atmosphere solar irradiance convoluted with the spectral response function of the satellite radiometer filter. $\mathrm{cal}_{\text {offset }}, \mathrm{cal}_{\text {slope }}$ and $f$ are specific MSG-2 radiometer calibration coefficients. Eq. (2) computes the corrective term describing Earth-sun distance seasonal variation $v(j)$. Result of this calibration is a 
narrowband bi-directional reflectance $R_{n b}$ specific to the spectral filter of the SEVIRI radiometer (Eq. (3)), function of $L_{S C}, v(j)$ and the sun zenith angle $\theta_{0}[36]$.

- Radiometer spectral filter narrowband to solar spectrum broadband conversion:

$$
R=M R_{n b}+B
$$

The Pinker and Laszlo [38] linear formula (4) converts the radiometer narrowband reflectance $R_{n b}$ to the solar spectrum broadband reflectance $R . M$ and $B$ are coefficients depending on the scene type (ocean, vegetation, desert, cloud over ocean, cloud over vegetation and cloud over desert).

- Anisotropy correction, where broadband bi-directional reflectance is converted to Top of Atmosphere (TOA) albedo $A$, which is independent of the satellite viewing angle:

$$
A\left(\theta_{0}\right)=R / f_{\text {aniso }}
$$

This correction is based on the formulae proposed by Manalo-Smith et al. [39]. The anisotropic factor $f_{\text {aniso }}$ is an analytical function of the viewing angles (sun zenith angle, satellite zenith angle and relative azimuth angle between satellite and sun viewing angle) depending on the scene type.

- Physical parameterization for clear and cloudy skies, where SSI is a function of TOA albedo and atmospheric transmittance:

$$
\begin{aligned}
& S S I=E_{0} v(j) \cos \theta_{0} T_{a} \text { in clear case } \\
& S S I=E_{0} v(j) \cos \theta_{0} T_{1} T_{c l} \text { in cloudy case }
\end{aligned}
$$

Within each equation, $E_{0}$ is the solar constant. Clear case, where $T_{a}$ is the clear sky atmospheric transmittance, uses the Frouin and Chertock [40] parameterization. Cloudy case, where $T_{1}$ is the sun-surface atmospheric transmittance, and $T_{c l}$ the cloud factor, is fully described in Brisson et al. [33]. 
Auxiliary inputs deriving from fixed atlas are the land-sea-coast pixel type, the mean altitude over the pixel (derived from a GTOPO30 Digital Elevation Model) and the prevailing land surface type. Monthly

climatologic fields contain broadband surface albedo over land, water vapor content, ozone content and horizontal visibility. Instantaneous fields include predicted water vapor content from ARPEGE meteorological model, and cloud type and cover.

Note that MSG images, where the sun zenith angle is greater than $80^{\circ}$ and satellite zenith angle is greater than $75^{\circ}$, are unprocessed.

The SSI scheme presents also some limits. The $0.1^{\circ}$ spatial resolution may be too low against the irradiance variability of mountainous or cloudy regions. Furthermore, re-mapping of the satellite image onto the SSI grid consists of the weighted average of original satellite pixels over a SSI pixel and, therefore, can limit accurate irradiance estimation over mixed/coast pixels, i.e. pixels including ocean and land surfaces. At last, hourly time resolution may restraint some subsequent solar applications.

For this work, we retrieved a reduced study area, covering a geographic square between $10^{\circ} \mathrm{N}$ and $15^{\circ} \mathrm{N}$ latitude and between $40^{\circ} \mathrm{E}$ and $45^{\circ} \mathrm{E}$ longitude.
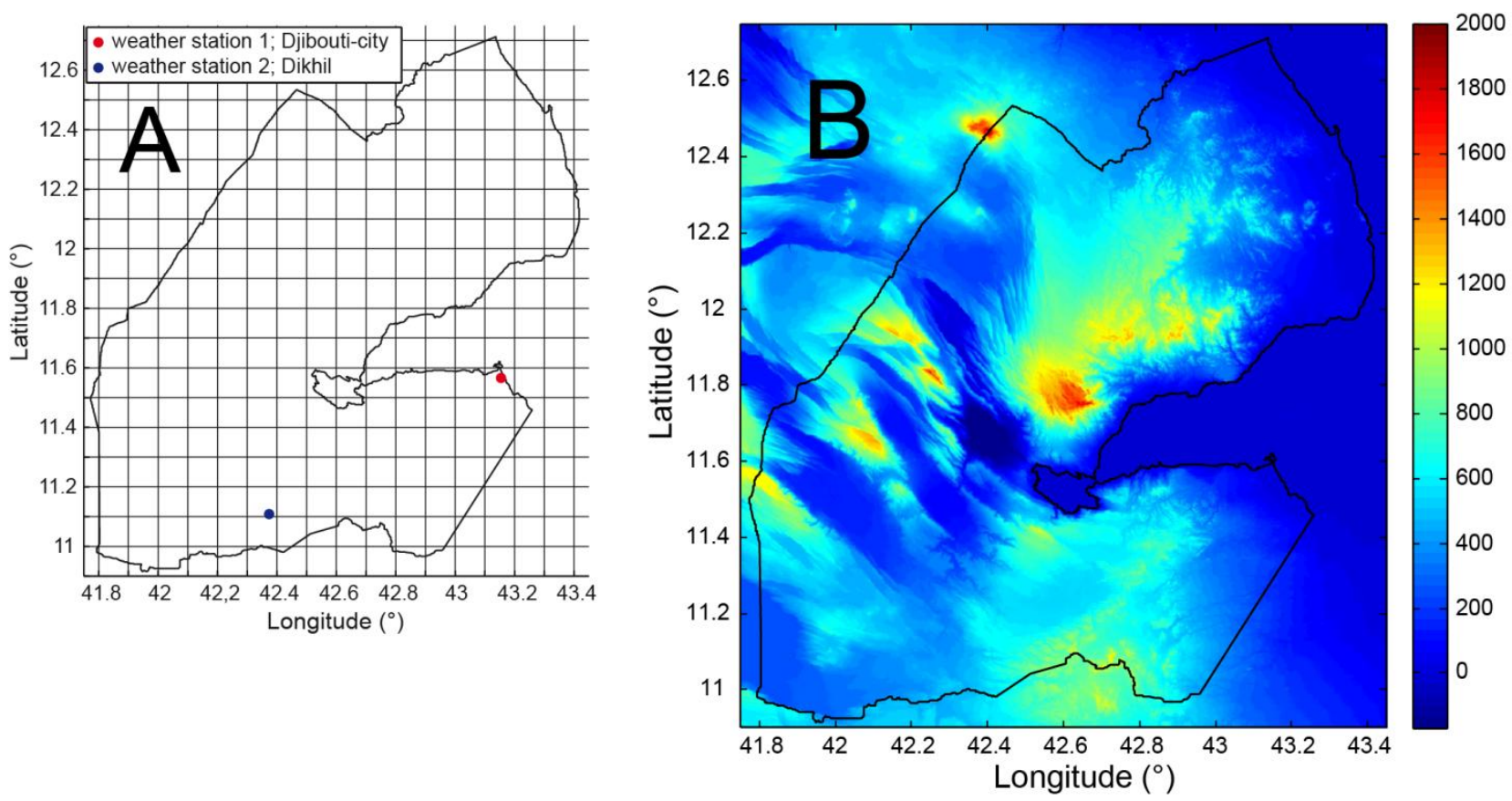

Figure 3: Comparison between SSI grid original resolution and DEM resolution. A) SSI grid, at 0.1 degree resolution, used in O\&SI SAF algorithm, with position of the two weather stations utilized during validation process. B) Reference Djibouti's SRTM-3 DEM used in this paper (elevation in $\mathbf{m})$. 
Finally, in order to focus on Djibouti, we limited this area between $10.9^{\circ} \mathrm{N}$ and $12.8^{\circ} \mathrm{N}$ latitude and between $41.7^{\circ} \mathrm{E}$ and $43.5^{\circ} \mathrm{E}$ longitude, corresponding to a 19 lines by 18 columns matrix. Figure 3.A. presents the study area with the corresponding SSI spatial grid.

\subsection{Evaluation of the O\&SI SAF SSI algorithm with ground data}

\subsubsection{Weather stations deployment}

Stations utilized for the O\&SI SAF SSI algorithm operational validation [35] present a great geographical covering disparity. Indeed, these stations are highly distributed in mid latitudes (Europe and North America), poorly distributed over the equator and low latitudes (Antilles and French Guyana), only one being located in southern hemisphere (South Africa) and none of them near Djibouti. Hence, as any radiometric network doesn't exist in Djibouti, we deployed, during the year 2010 and in cooperation with the CERD, two Vantage Pro 2 Davis Instruments temporary weather stations across the country, in order to assess and validate global solar horizontal radiation estimated through the SSI model. These stations use silicon-photodiode pyranometers measuring global horizontal irradiation (reference $n^{\circ} 6450$; precision $= \pm$ $5 \%$; spectral range $=0.4-1.1 \mu \mathrm{m}$; value range $=0-1800 \mathrm{~W} / \mathrm{m}^{2} ;$ temperature coefficient $=-0.12 \% /{ }^{\circ} \mathrm{C}$ ) and other standard sensors (temperature, relative humidity, pressure, wind speed and rain gauge). Note that even though photodiode pyranometers have a lower spectral response than thermopile pyranometers, they are calibrated, i.e. influence of solar spectrum, angle of incidence and temperature on the pyranometer's response are corrected, to estimate broadband irradiance [41]. The limited number of weather stations and the choice to have only global horizontal irradiation sensors were mostly due to economic and logistic reasons. It was not possible to deploy high-quality sensors throughout the country because of safety and climatic conditions. Therefore, the authors preferred to invest in robust weather stations which presented the advantage to also measure typical climatic parameters, although they measured irradiation with a 5\% error and didn't allow installing tilted pyranometric sensors. However, we have moved the two current stations in January 2012, but corresponding SSI data are still unavailable because of a data reprocessing at Meteo- 
France. Finally, it is also important to note that before this study, no solar sensors had ever been deployed in the country.

Furthermore, the selection of the 2 weather station sites was influenced by several important requirements. Firstly, from a solar radiation point of view, we had to install the stations in places corresponding to both distant and quite different climatologically SSI pixels. Secondly, for security reasons, it was necessary to select safe places, as public schools or administrations. Finally, the last constraint was about logistics, as station data had to be accessed quickly and permanently. For all these reasons, we decided to position the first station in the CERD at Djibouti-city (weather station 1; measuring period: 04/06/2010 - 12/17/2011) and the second station, in the prefecture of Dikhil, in the South West country (weather station 2; measuring period: 06/27/2010 - 12/05/2011), corresponding to "coast" and "land" type SSI pixels, respectively. Figure 3.A shows location of the 2 temporary stations within the territory.

\subsubsection{Comparison between estimated and measured data: method and results}

The comparison process evaluates quality of the whole solar atlas computation rather than only the O\&SI SAF algorithm. To accomplish this assessment, we therefore compared irradiation data and not irradiance data. Indeed, the purpose of this study is the evaluation of the solar resource throughout Djibouti in order to size future solar systems across the country, including stand-alone PV systems [13]. So, it was necessary to compute accurate energy data with the best possible time step. If in our case this step is already fixed by the hourly time resolution of SSI data, it is important to note that sizing solar power systems also depends on output load profiles. These profiles vary over the day and then require a better time resolution. However, regarding to the remote populations without access to electricity, it is quite difficult to characterize load profiles with precision and an hourly time step seems therefore to be an acceptable compromise. The satellite-based solar atlas was hence computed with the same time resolution.

Ground-based global horizontal irradiation data were measured by the photodiode pyranometers of the weather stations over the selected recording interval (time step of 5 and 10 minutes for station 1 and station 2 , respectively). We checked quality of weather station data, reprocessed them if necessary, especially 
possible time shifts, and selected only the days without any missing data. These missing data are typically due to different errors like wireless communication errors between the station and the acquisition data box or human manipulation errors when data were retrieved. As a result, proportion of missing daily ground-based datasets corresponds to $10.64 \%$ for station 1 and $25.62 \%$ for station 2 . Computation of hourly ground-based irradiation data was then achieved by summing these data over each hour. Finally, daily and monthly datasets were retrieved by summing hourly data over each day and month.

Then, in order to properly interpolate and integrate SSI data, it was necessary to know the exact registration time of the MSG image over the study area. This time depends on the study area's location and on the satellite image acquisition's start time. In our case, SSI model is based on MSG images which begin to be scanned by the SEVIRI imaging radiometer at HH:15 UTC. The resulting time difference linearly varies with the line position within the satellite image [42] and corresponds approximately to 8 minutes for Djibouti $\left(2200^{\text {th }}\right.$ line $)$. Hence, the registration time of each slot is about HH:23 UTC and all computed hourly SSI data correspond to 4:23, 5:23, 6:23, 7:23, 8:23, 9:23, 10:23, 11:23, 12:23, 13:23 and 14:23 UTC. MSG images corresponding to 3:23 and 15:23 UTC are still unprocessed because of a sun zenith angle greater than $80^{\circ}$ over the year.

To control SSI model's validity and accuracy over the study area, we used some well known statistical indices as suggested by Iqbal [43] and Notton et al. [44], including Root Mean Square Error (RMSE), Mean Bias Error (MBE) and Correlation Coefficient (CC), defined as follow:

$$
\begin{aligned}
& R M S E=\sqrt{\frac{\sum_{i=1}^{n}\left(I_{i}^{\prime}-I_{i}\right)^{2}}{N}}\left(\mathrm{Wh} / \mathrm{m}^{2}\right) \\
& M B E=\sqrt{\frac{\sum_{i=1}^{n}\left(I_{i}^{\prime}-I_{i}\right)}{N}\left(\mathrm{Wh} / \mathrm{m}^{2}\right)} \\
& C C=\frac{\sum_{i=1}^{n}\left(I_{i}-\bar{I}\right)\left(I_{i}^{\prime}-\overline{I^{\prime}}\right)}{\sqrt{\sum_{i=1}^{n}\left(I_{i}-\bar{I}\right)^{2} \sum_{i=1}^{n}\left(I_{i}^{\prime}-\overline{I^{\prime}}\right)^{2}}}\left(\mathrm{Wh} / \mathrm{m}^{2}\right)
\end{aligned}
$$


And their relative contribution, Relative Root Mean Square Error (RRMSE) and Relative Mean Bias Error (RMBE), defined as:

$$
\begin{aligned}
& R R M S E=R M S E / \bar{I}(\%) \\
& R M B E=M B E / \bar{I}(\%)
\end{aligned}
$$

Where $I_{i}^{\prime}$ is the ith estimated global horizontal irradiation value, $I_{i}$ the ith measured value, $\overline{I^{\prime}}$ the estimated mean value, and $\bar{I}$ the measured mean value.

Global horizontal irradiation data comparison was based on daily SSI datasets where all SSI hourly slots have been computed by the O\&SI SAF over the specified weather station locations. The clearness index was computed for each hourly slot and linearly one-minute interpolated. One-minute SSI data were then retrieved from clearness index data and integrated over each hour, resulting in hourly estimated global irradiation data. Daily estimates consist of hourly data amounts over each day. Finally, in order to recover monthly climatic characteristics, monthly data were retrieved for the months where at least 20 days were used for comparison between estimates and ground-based measurements.

We then considered 2 approaches to compare irradiation data. At first, in order to evaluate SSI process through the solar atlas computation, we limited the SSI dataset to days without any missing or erroneous SSI data and from which unprocessed data (sun zenith angle greater than $80^{\circ}$ ) were removed. In that case, estimated irradiation was retrieved by integrating SSI data between first and last time slots and measured irradiation was retrieved by summing corresponding ground-based irradiation data. Then, to evaluate quality of the solar atlas, we considered all days, integrated between real sunrise and sunset hours, where missing, erroneous and unprocessed irradiance data were retrieved by interpolating the corresponding clearness index data. Note that this quality assessment of the entire atlas is also necessary because of the further disaggregation methodology which mainly reduces global irradiation near sunrise and sunset times. 
Table 1: Comparison between measured and estimated global horizontal irradiation

\begin{tabular}{|c|c|c|c|c|c|c|c|c|c|c|c|c|}
\hline & & \multicolumn{5}{|c|}{$\begin{array}{c}\text { Djibouti-city }\left(11,5658^{\circ} \mathrm{N} ; 43,1543^{\circ} \mathrm{E} ; 7 \mathrm{~m}\right) \\
\text { "coast" pixel }\end{array}$} & \multirow{2}{*}{\multicolumn{3}{|c|}{ Restricted set }} & \multicolumn{3}{|c|}{$\begin{array}{l}\left.77^{\circ} \mathrm{N} ; 42,3736^{\circ} \mathrm{E} ; 498 \mathrm{~m}\right) \\
\text { "land" pixel }\end{array}$} \\
\hline & & \multicolumn{2}{|c|}{ Restricted set } & \multicolumn{3}{|c|}{ Whole set } & & & & & Whole se & \\
\hline & Monthly & Daily & Hourly & Monthly & Daily & Hourly & Monthly & Daily & Hourly & Monthly & Daily & Hourly \\
\hline Sample size & 17 & 537 & 5690 & 17 & 548 & 7213 & 12 & 386 & 4070 & 13 & 392 & 5103 \\
\hline $\operatorname{RMSE}\left(\mathrm{Wh} / \mathrm{m}^{2}\right)$ & 6118,4 & 450,8 & 73,9 & 6783,8 & 471,2 & 68,2 & 7020,0 & 342,6 & 60,9 & 6501,5 & 344,1 & 57,2 \\
\hline RRMSE (\%) & 3,92 & 8,02 & 13,93 & 4,16 & 8,10 & 15,44 & 4,33 & 5,93 & 11,12 & 3,90 & 5,74 & 12,43 \\
\hline $\operatorname{MBE}^{1}\left(\mathrm{Wh} / \mathrm{m}^{2}\right)$ & $-1436,1$ & $-70,4$ & $-6,6$ & $-2473,2$ & $-105,2$ & $-8,0$ & 3664,5 & 130,7 & 12,4 & 2322,6 & 82,6 & 6,3 \\
\hline $\operatorname{RMBE}^{1}(\%)$ & $-0,92$ & $-1,25$ & $-1,25$ & $-1,51$ & $-1,81$ & $-1,81$ & 2,26 & 2,26 & 2,26 & 1,39 & 1,38 & 1,38 \\
\hline $\mathrm{CC}$ & 0,9638 & 0,8949 & 0,9654 & 0,9620 & 0,8950 & 0,9768 & 0,9665 & 0,9382 & 0,9792 & 0,9718 & 0,9350 & 0,9856 \\
\hline
\end{tabular}

${ }^{1}$ Negative bias means underestimation

Table 1 presents results of the assessment method, for both stations. As daily irradiations correspond to the sum of hourly irradiations, RMBE is the same for all daily and hourly datasets. Station 2 presents the best results for all sets. Furthermore, for both the restricted and whole sets, solar atlas computation slightly overestimates and underestimates irradiation for Dikhil and Djibouti-city, respectively, and presents, obviously, the best results for monthly comparison.

Thus, for the restricted set, daily RRMSE is about $5.93 \%$ for station 2 against $8.02 \%$ for station 1 . Daily bias is near to zero for both stations (2.26\% for Dikhil and $-1.25 \%$ for Djibouti-city) and station 2 presents a daily $\mathrm{CC}$ of about 0.94 against 0.89 for station 1 . Hourly irradiation data comparison reasonably increases RRMSE for both stations (11.12\% and $13.93 \%$ for Dikhil and Djibouti-city, respectively). Furthermore, since the second method mainly increases the number of underestimated global irradiation data near sunrise and sunset times, MBE and RMBE decrease from the restricted set to the whole set, while hourly CC increases. Also, daily and monthly CC doesn't change while RRMSE stays constant for Djibouti-city and decreases for Dikhil. Finally, the complete solar atlas process slightly increases hourly RRMSE from $11.12 \%$ to $12.43 \%$ for Dikhil and from $13.93 \%$ to $15.44 \%$ for Djibouti-city.

Pixel type ("land/sea") and frequent cloudy spells over the capital, because of the sea and the Intertropical Convergence Zone (ITCZ) proximity, coupled with hourly time step and low spatial resolution, can explain worse results for the station 1. 

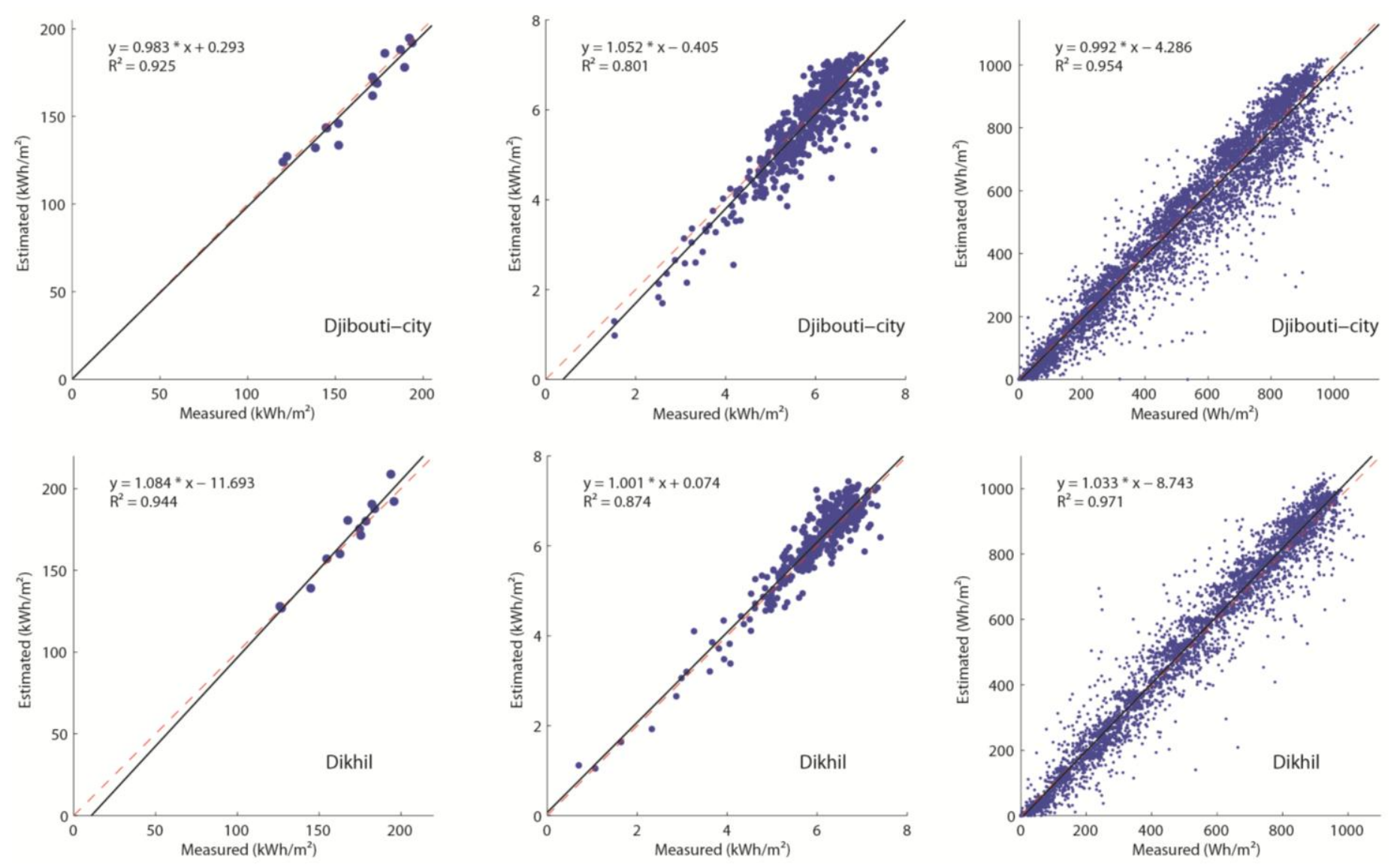

Figure 4: Monthly (a), daily (b) and hourly (c) estimated versus measured irradiation scatter plots for each station (Djibouti-city above and Dikhil below), with black regression line and red (1:1) dashed line. Regression equation and determination coefficient are given for each plot.

Scatter plots for the whole solar atlas computation, presented in figure 4, confirm this data profile tendency, with a good correlation between satellite-based model and ground measurements for monthly, daily and hourly irradiation at Dikhil, while the comparison for Djibouti-city presents data more scattered on both side of the 1-to-1 line. For the monthly scatter plots especially, the more distant points from the 1-to-1 line correspond to April and May, the cloudiest months.

As previously said, no O\&SI SAF validation has ever been realized over eastern Africa. However, the different validation campaigns over low and mid latitudes led to more or less the same results [34,35]. Assessment over equatorial Atlantic in 2006 had shown hence both negligible and negative bias, and hourly and daily RRMSE of 16.4\% and 8.2\%, respectively. Also, experiment from January 2004 to April 2006, with outnumbered and more geographically dispersed in situ measurements, had presented very insignificant bias and hourly and daily RRMSE of $17 \%$ and $8.7 \%$, respectively. Furthermore, a quick comparison with some other well known satellite-derived SSI methods like Heliosat or Heliosat-II reported in the literature [45] also gives consistency to O\&SI SAF SSI data over Djibouti. For instance, the Heliosat-II method has 
presented, from measured data of 35 European stations, overestimated bias from $2 \%$ to $5 \%$ and daily

RRMSE of 20\%, $16 \%$ and $10 \%$ for January, April and July respectively. Among these results, the RRMSE in July is probably the most interesting since the Djiboutian climate can be compared to the European climate during summer.

To conclude, in spite of low spatial and temporal SSI resolutions, the complete process error is low for highquality pixels (i.e. "land" pixels with constant meteorological conditions) and stays acceptable for complex pixels (i.e. "mixed" pixels with more variable meteorological conditions than others). Although SSI products could be improved, principally with time resolution, to reduce meteorological variability effect, and spatial resolution, to reduce pixel surface type problem, they are acceptable over Djibouti, a country with preferential conditions, including a desert climate and a yearly global irradiation greater than $2000 \mathrm{kWh} / \mathrm{m}^{2}$.

\section{The downscaled solar atlas of the Republic of Djibouti}

This section presents the method we used to build the new disaggregated irradiation maps of the country. The methodology consists of the use of a 3 arc second ( $~ 90$ meters at the equator) Digital Elevation Model (DEM) in order to downscale SSI, at $0.1^{\circ}$ resolution, by considering shading effects and intra-pixel variation of elevation. However, since the maximum resolution of the SEVIRI channels used to retrieve original SSI data being about $3 \mathrm{~km}$ at the nadir [30], it doesn't allow to observe under-scaled cloud. Therefore, the disaggregation method only retrieves terrain-related effects like obstruction or elevation gradient and doesn't evaluate the possible micro climate variations within Meteosat pixels. Finally, if, according to Ruiz-Arias et al. [14] and Bosch et al. [15], this method allows improving accuracy of the final solar atlas, it is important to note that the design goal of the authors was above all to improve geographic information of irradiation maps.

\subsection{Processing scheme}




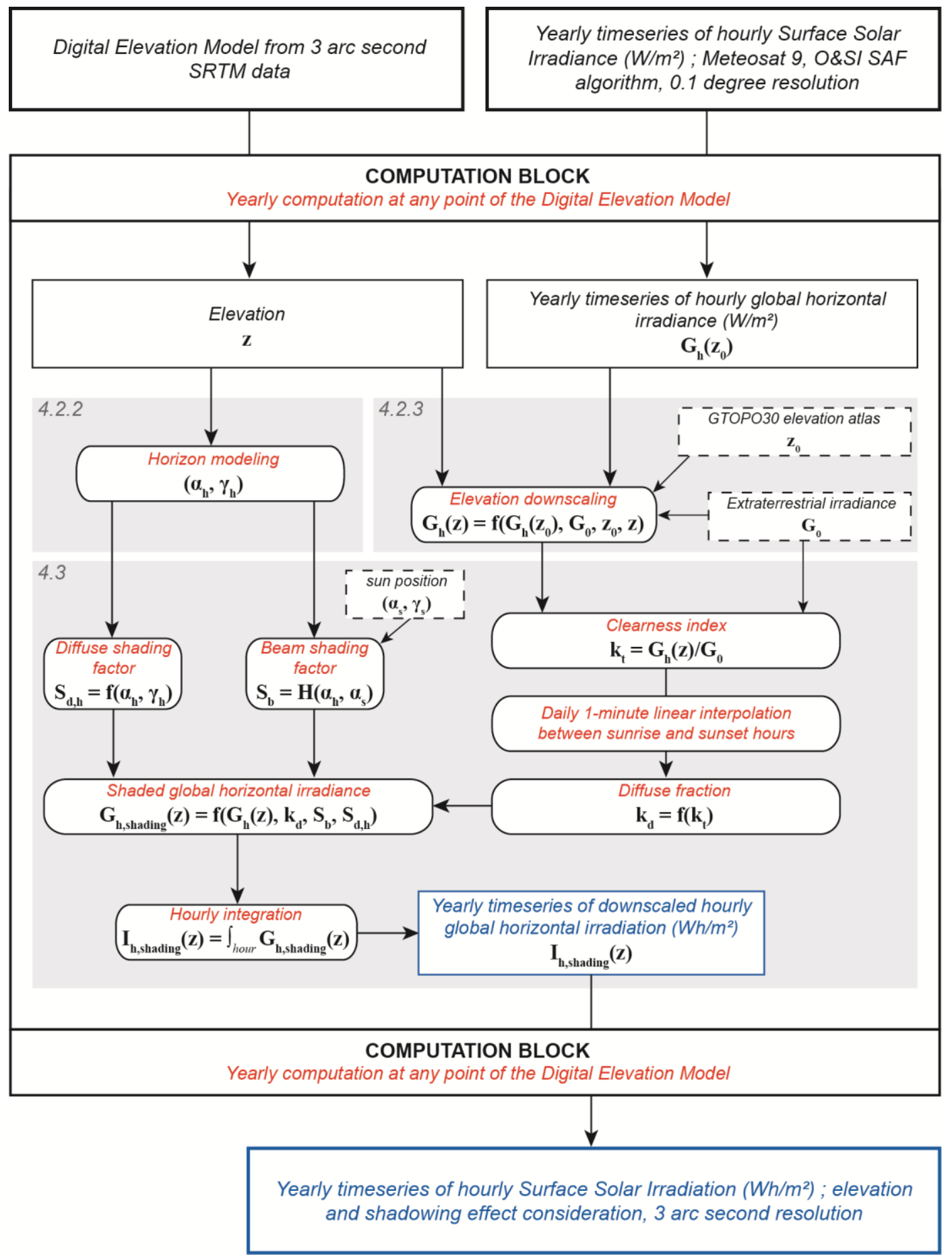

Figure 5: Processing scheme of the hourly SSI disaggregation methodology (data inputs are written in black italic font, processing data in red italic, and outputs in blue italic). Each numbered gray section of the computation block refers to its corresponding section in the text.

In order to realize mapping disaggregation, we developed a specific program following the processing scheme described in figure 5.

Some models describing terrain shadowing exist, at present time, and were implemented within software.

Some of them just compute horizon for a given location, others combine horizon model with solar radiation estimate. Thus, many Geographical Information Systems (GIS) use their own DEM-based models to estimate solar radiation over mountainous areas [46]. Nevertheless, these GIS software still utilize simplified 
atmospheric parameterizations which limit their use for operational modeling $[14,46]$. In particular, they do not allow disaggregating external solar maps provided by another device. Therefore, to downscale satellitebased irradiance maps, it would have been necessary, in the one hand, to compute horizon angle for each DEM pixel with a GIS or another specific device and, in the other hand, to realize irradiance splitting and elevation correction by programming models we selected. Such a processing scheme presents, obviously, important performance limitations. For these reasons, in order to avoid slow computation time due to both horizon modeling and data transfer between different programming languages, we preferred to implement a global modeling program, combination of our own horizon model with elevation correction and irradiance splitting models. In comparison to the size of the whole dataset to process, this solution presented the highest possible computing efficiency.

As shown in figure 5, the 2 main inputs required for the process are DEM and yearly timeseries of hourly SSI corresponding to the defined study area. The computation block calculates horizon, elevation correction and irradiance splitting for each DEM pixel over a year. Extraterrestrial irradiance and global elevation atlas GTOPO30 are required to achieve elevation correction, while sun position is necessary to compute the beam shading factor. Then, extraterrestrial irradiance is also necessary to determine clearness index in order to split global irradiance into beam and diffuse components. Finally, after re-aggregation and integration, the computation block result is a yearly timeseries of disaggregated hourly irradiation for each DEM pixel. After all, result of the whole disaggregation process is the Djibouti's downscaled hourly irradiation atlas, i.e. a yearly timeseries of disaggregated hourly irradiation maps of the country.

The following sub-sections describe each processing step in detail and correspond to numbered gray sections within the computation block of figure 5.

\subsection{DEM downscaling}

\subsubsection{The Shuttle Radar Topography Mission}


Current DEMs were provided by the Shuttle Radar Topography Mission (SRTM), which occurred in February 2010, aboard the Endeavour space shuttle. By using Interferometric Synthetic Aperture Radar (InSAR), the mission recorded elevation data at 1 arc second resolution, from $80 \%$ of the Earth, between $60^{\circ} \mathrm{N}$ and $57^{\circ} \mathrm{S}[47,48]$. Voids due to lack of contrast in the radar image were filled in via a spatial filtering technique [49]. Finally, SRTM data were compiled by the Consultative Group for International Agriculture Research Consortium for Spatial Information (CGIAR-CSI) and are available through their web site [50]. SRTM data at 1 arc second resolution (SRTM-1) are available only for the USA, while SRTM data at 3 arc second resolution (SRTM-3) are available globally.

Figure 3.B shows the Djibouti's SRTM-3 DEM used in this work, corresponding to a $2221 \times 2041$ elevation matrix, comprised between $10.9^{\circ} \mathrm{N}$ and $12.75^{\circ} \mathrm{N}$ latitude, and between $41.75^{\circ} \mathrm{E}$ and $43.45^{\circ} \mathrm{E}$ longitude.

\subsubsection{Horizon modeling}

We developed our horizon model within a computing performance and flexibility strategy. In comparison to the great amount of processing data, it was necessary to conciliate horizon error and computing speed. For assessing and validating this model, we chose to compare, during the year 2010, estimations versus measured horizons in Corsica Island, France. Indeed, if the availability of theodolite systems was the main reason, this island also presents a high variety of topography patterns within a little area and, therefore, was an interesting region to retrieve a large diversified sample of measured horizons without difficulty.

To measure these horizons, we used a Builder 100 Leica Geosystems theodolite (azimuth angle accuracy: 9'; elevation angle accuracy: 6"), a very accurate instrument helping land surveyors to measure slope and aspect of a terrain. Furthermore, in order to check the consistency of our horizon model, we compared it against 2 other horizon models, the Carnaval Open Source, developed by the French desk study Incub, and r.horizon [51], part of the radiation model r.sun [52] implemented in the GRASS GIS Open Source.

Carnaval uses France's SRTM-3 DEM already implemented within software and computes horizon for a given point, intended to be used later in a solar system sizing software. Our model and GRASS use SRTM-3 DEMs loaded by user. They are part of global models which compute, at last, DEM-based radiation maps, 
by using disaggregation for our model and the r.sun radiation model for GRASS. Note that r.horizon can be used in 2 different ways. In the one hand, it can determine shadowing for a whole map by computing angular elevation in a specific azimuth direction. In the other hand, it can compute horizon for a given DEM pixel. It is this approach we chose for comparison. Among the 3 tested models, ours presents the lowest computing time before r.horizon and Carnaval, respectively. Moreover, as our horizon model has been directly incorporated within a global downscaling model, the total performance benefit is very important compared to the use of external models.

Finally, to realize this comparison study, we used RRMSE, RMBE and CC, the statistical indices defined in section 1.2.2.

Table 2: Horizon data accuracy assessment through 10 Corsican sites for our model, Carnaval software and GRASS GIS.

\begin{tabular}{|c|c|c|c|c|c|c|c|c|c|c|c|c|c|}
\hline \multirow[b]{2}{*}{ Site } & \multirow[b]{2}{*}{ Latitude } & \multirow[b]{2}{*}{ Longitude } & \multirow[b]{2}{*}{ Altitude (m) } & \multirow[b]{2}{*}{ Sample size } & \multicolumn{3}{|c|}{ Our model } & \multicolumn{3}{|c|}{ Carnaval software } & \multicolumn{3}{|c|}{ GRASS GIS (r.horizon) } \\
\hline & & & & & $\mathrm{CC}$ & RRMSE (\%) & $\operatorname{RMBE}(\%)$ & $\mathrm{CC}$ & RRMSE (\%) & $\operatorname{RMBE}(\%)$ & $\mathrm{CC}$ & RRMSE (\%) & $\operatorname{RMBE}(\%)$ \\
\hline Ajaccio & $41.9255^{\circ} \mathrm{N}$ & $8.7802^{\circ} \mathrm{E}$ & 0 & 61 & 0.9679 & 10.82 & 3.56 & 0.9685 & 10.15 & 0.44 & 0.9658 & 11.04 & 2.99 \\
\hline Calvi & $42.554^{\circ} \mathrm{N}$ & $8.792^{\circ} \mathrm{E}$ & 1 & 45 & 0.9934 & 3.13 & -0.47 & 0.9939 & 3.08 & -0.92 & 0.9954 & 2.63 & -0.73 \\
\hline Lozari & $42.64^{\circ} \mathrm{N}$ & $9.0149^{\circ} \mathrm{E}$ & 1 & 51 & 0.9887 & 6.36 & -1.66 & 0.9949 & 4.83 & -2.45 & 0.9920 & 5.55 & -1.33 \\
\hline Bastia & $42.5452^{\circ} \mathrm{N}$ & $9.4806^{\circ} \mathrm{E}$ & 8 & 45 & 0.9988 & 2.72 & 1.84 & 0.9985 & 2.36 & -0.88 & 0.9986 & 2.30 & 0.92 \\
\hline Solenzara & $41.9312^{\circ} \mathrm{N}$ & $9.3903^{\circ} \mathrm{E}$ & 19 & 56 & 0.9984 & 2.68 & 2.02 & 0.9983 & 2.03 & -0.78 & 0.9981 & 2.11 & 0.98 \\
\hline Tavignano & $42.1831^{\circ} \mathrm{N}$ & $9.3782^{\circ} \mathrm{E}$ & 80 & 73 & 0.9268 & 20.39 & -13.58 & 0.7157 & 56.31 & -50.86 & 0.9233 & 17.85 & -9.77 \\
\hline Castellare & $42.2883^{\circ} \mathrm{N}$ & $9.2272^{\circ} \mathrm{E}$ & 325 & 73 & 0.9720 & 20.41 & -16.84 & 0.8862 & 43.77 & -35.84 & 0.9552 & 18.87 & -12.32 \\
\hline Venaco & $42.2727^{\circ} \mathrm{N}$ & $9.2142^{\circ} \mathrm{E}$ & 352 & 70 & 0.9784 & 28.55 & -17.18 & 0.8440 & 55.01 & -31.72 & 0.9431 & 25.10 & -10.10 \\
\hline Corte & $42.3011^{\circ} \mathrm{N}$ & $9.1712^{\circ} \mathrm{E}$ & 366 & 68 & 0.9972 & 4.06 & -1.58 & 0.9947 & 5.89 & -2.73 & 0.9973 & 3.80 & -0.88 \\
\hline Soveria & $42.344^{\circ} \mathrm{N}$ & $9.1744^{\circ} \mathrm{E}$ & 514 & 73 & 0.9947 & 8.40 & -5.15 & 0.9689 & 17.75 & -11.48 & 0.9944 & 6.78 & -2.97 \\
\hline Total & & & & 615 & 0.9785 & 21.00 & -9.05 & 0.8312 & 50.90 & -24.88 & 0.9765 & 18.62 & -6.19 \\
\hline
\end{tabular}

Table 2 presents results of the comparison between measured horizons and horizons estimated through the 3 models. Our model and r.horizon present the more homogeneous correlation results for the whole set, with a CC equal to 0.9785 and 0.9765 , respectively. The 2 models provide close RRMSE ( $21 \%$ and $18.62 \%$ for our model and GRASS, respectively) while GRASS presents the best bias (-6.19\% against $-9.05 \%)$. At last, Carnaval shows the lowest quality results for the whole set with a CC equal to 0.8312, a RRMSE over 50\% and a negative bias of about $25 \%$. If we compare against the processing performance, our model is a good compromise between computation speed and horizon accuracy. Nevertheless, if we look at these results more carefully, we note that some horizons are well fitted by the models (for instance Bastia, Corte, Solenzara or Calvi) whereas some others present high relative errors. By neglecting some errors due to measures (errors on elevation measures or on the geo-referencing of the horizon site) or provided by horizon 
models, it is possible to explain and forecast the horizon error by mainly correlating it to the DEM original absolute error. However, since the DEM vertical RMSE is different from a geographical area to another $[53,54]$, we preferred to develop an error sensitivity coefficient which was completely independent from the DEM error.

In order to understand the expression of such a coefficient, let us consider a point of a given measured horizon. SRTM was expected to generate DEMs with a vertical RMSE of 16 m $[47,48]$. Angular elevation absolute error on this point is, therefore, correlated to the distance between this point and the observer point. Moreover, although it is difficult to take into consideration, the lower the distance to the point is, the lower the number of DEM points describing this horizon is, for a given DEM resolution. So, if the horizon is strongly discontinued, the error will probably increase.

Then, according to Miliaresis and Paraschou [53] and Gorokhovich and Voustianiouk [54], vertical RMSE of DEMs is strongly dependent on the terrain slope. Thus, error is also linked to the elevation angle of the point. The last useful DEM parameter helping to predict model accuracy is, obviously, the DEM resolution. From these simple observations, in order to predict absolute error of a given horizon, we defined the following average error sensitivity coefficient:

$$
S_{\text {horizon }}=\frac{R_{D E M}}{N} \sum_{k=1}^{N} \frac{\alpha_{k}}{d_{k}}
$$

where $R_{D E M}$ is the DEM resolution, $\alpha_{k}$ the horizon elevation angle of the k point, $d_{k}$ the calculated distance from the observer point to the horizon $\mathrm{k}$ point and $N$, the number of measured points. Hence, the higher the coefficient $S_{\text {horizon }}$ is, the more important the error on the modeled horizon will probably be. To verify validity of such a coefficient, we observed evolution of both RMSE and MBE of the whole set with $S_{\text {horizon }}$, for our model, r.horizon and Carnaval.

The model robustness study, shown in figure 6, presents both the error sensitivity analysis and the comparison between Corte and Tavignano, sites with $S_{\text {horizon }}$ equal to 0.14 and 6.86, respectively. The study shows, as expected, that RMSE increases with $S_{\text {horizon }}$. Moreover, to evaluate strength of the correlation between RMSE and $S_{\text {horizon }}$, we have computed the CC. Hence, for our model, r.horizon and Carnaval, it is 
respectively equal to $0.9786,0.9729$ and 0.9603 at a 0.01 level of significance. At the same time, we can observe that MBE decreases. The comparison between Corte and Tavignano illustrates this tendency.

Horizon model fits Corte accurately when $S_{\text {horizon }}$ is low whereas the other site, with a high $S_{\text {horizon }}$, is clearly underestimated. However, studies realized by Miliaresis and Paraschou [53] in Crete, an island with similar topographic features than Corsica, and by Gorokhovich and Voustianiouk in the USA and Thailand [54], didn't show any underestimate error tendency. So, the resulting horizon error tendency was not really predictable. Consequently, we can conclude that horizon modeling step of the disaggregation process tends to underestimate or overestimate topography effects and, so, to overestimate or underestimate irradiation over regions where horizons are important, close or a combination of both.

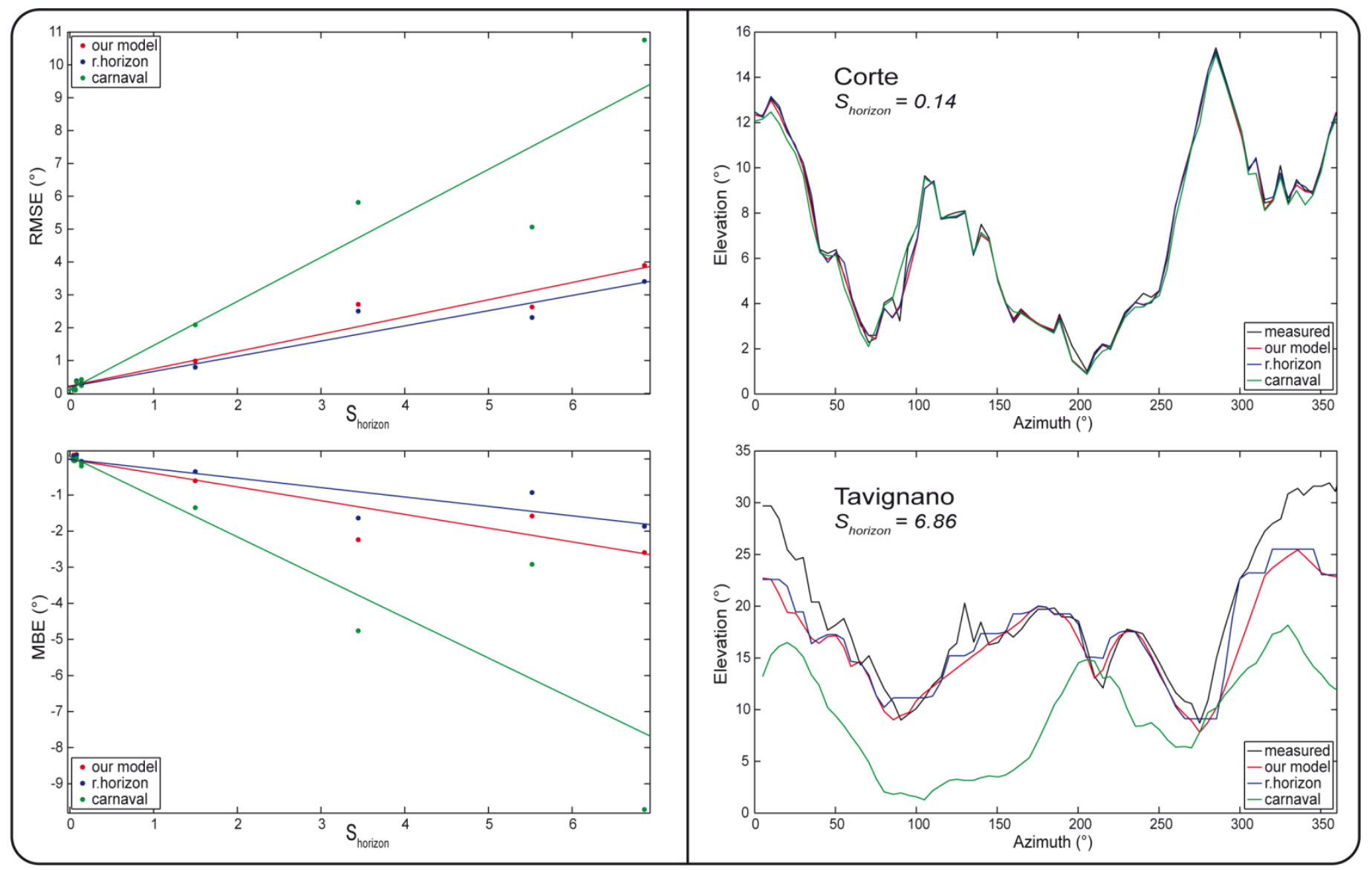

Figure 6: Model robustness study for our model, r.horizon and Carnaval. The left side presents sensitivity analysis, i.e. evolution of RMSE $\left({ }^{\circ}\right)$ and $\operatorname{MBE}\left({ }^{\circ}\right)$ with the average coefficient of error sensitivity $S_{\text {horizon }}$. The right side shows horizon fitting examples for Corte and Tavignano sites, with low and high $S_{\text {horizon }}$, respectively.

\subsubsection{Elevation downscaling}


As mentioned in section 1.1.3., the SSI scheme takes altitude into consideration by using mean elevation derived from the 30 arc second GTOPO30 DEM. One SSI pixel uses the $12 \times 12$ elevation matrix average of the GTOPO30 DEM and corresponds to a $120 \times 120$ elevation matrix in the SRTM-3 DEM. Thus, the intra pixel elevation variance can be very high for some regions. So, to determine the global horizontal irradiance $G_{h}$ on a DEM pixel at an altitude $z$ from the mean GTOPO30 altitude $z_{0}$, we used the following empirical correction established by Wahab et al. [55] over the northern Africa:

$$
G_{h}(z)=G_{0} \exp (-\tau(z))
$$

where $G_{0}$ is the global horizontal extraterrestrial irradiance; $\tau(z)$ characterizes the optical thickness of the atmosphere:

$$
\tau(z)=\tau\left(z_{0}\right) \beta^{\left(z_{0}-z\right)}, \beta=1.20
$$

with

$$
\tau\left(z_{0}\right)=-\ln \left(G_{h}\left(z_{0}\right) / G_{0}\right)
$$

Note that we can use this relation with the global horizontal irradiance $G_{h}$ over Djibouti since Wahab et al. demonstrated the correction availability for all skies when altitude $z$ ranges from 0 to $3 \mathrm{~km}$.

\subsection{Irradiance splitting and shading consideration}

To take into account shadowing effects, it was necessary to decompose global horizontal irradiance $G_{h}(z)$ into the beam horizontal and diffuse horizontal components, $G_{b, h}(z)$ and $G_{d, h}(z)$, by using a diffuse fraction model $k_{d}$, such as:

$$
\left\{\begin{array}{c}
G_{b, h}(z)=\left(1-k_{d}\right) G_{h}(z) \\
G_{d, h}(z)=k_{d} G_{h}(z)
\end{array}\right.
$$

However, if many empirical models have been established for splitting global irradiance and global irradiation, none of them have been validated over Djibouti.

Hence, we have computed, in first order, several diffuse fraction models to observe final differences between resulting solar maps. We used three models defined as functions of the only clearness index $k_{t}$. 
Indeed, because of the great surface to process, we preferred to implement the least possible inputs in order to compute the complete solar atlas with high time calculation performances.

Firstly, we computed the Ruiz-Arias regressive diffuse fraction model [56] and the Erbs model [57], as they were already used within disaggregation methodologies $[14,15]$ and gave good results. Then, we compared these models to a third one, the CLIMED2 model [58], which gave accurate results over the north Mediterranean belt area, including Corsica Island [44].

Eq. (18), Eq. (19) and Eq. (20) present the Ruiz-Arias, Erbs and CLIMED2 models, respectively:

$$
\begin{aligned}
& k_{d}=0.952-1.041 \exp \left(2.300-4.702 k_{t}\right) \\
& k_{d}=\left\{\begin{array}{cl}
1-0.09 k_{t} & \text { for } 0 \leq k_{t} \leq 0.22 \\
0.9511-0.1604 k_{t}+4.388 k_{t}^{2} & \text { for } 0.22<k_{t} \leq 0.80 \\
-16.638 k_{t}^{3}+12.336 k_{t}^{4} & \text { for } k_{t}>0.80 \\
0.165 & \text { for } k_{t} \leq 0.21 \\
0.995-0.081 k_{t} & \text { for } 0.21 \leq k_{t} \leq 0.76
\end{array}\right. \\
& k_{d}=\left\{\begin{array}{cl}
0.724+2.738 k_{t}-8.32 k_{t}^{2}+4.967 k_{t}^{3} & \text { for } k_{t}>0.76 \\
0.180 &
\end{array}\right.
\end{aligned}
$$

where $k_{t}=G_{h}(z) / G_{0}$

Note that the diffuse fraction $k_{d}$ has the 1-minute time resolution of the clearness index $k_{t}$, which was computed from the previous elevation-downscaled irradiance and then linearly interpolated at a 1-minute time step in order to get the maximum precision over the further integration of shading effects into hourly irradiation. Finally, global irradiance was also recalculated at a 1-minute time resolution from the clearness index.

Then, to consider shading effects, we computed the direct shading factor $S_{b}$ and the isotropic horizontal diffuse shading factor $S_{d, h}$, as described by Quaschning and Hanitsch [59].

If $\alpha_{S}^{\gamma_{S}}$ is the sun elevation angle in the sun azimuth angle direction $\gamma_{S}$ and $\alpha_{H}^{\gamma_{S}}$, the horizon elevation angle in the sun azimuth angle direction, the direct shading factor $S_{b}$ is described by the following Heaviside function: 


$$
S_{b}=H\left(\alpha_{S}^{\gamma_{S}}, \alpha_{H}^{\gamma_{s}}\right)=\left\{\begin{array}{cl}
0 & \text { if } \alpha_{S}^{\gamma_{s}}>\alpha_{H}^{\gamma_{s}} \\
1 / 2 & \text { if } \alpha_{S}^{\gamma_{S}}=\alpha_{H}^{\gamma_{S}} \\
1 & \text { if } \alpha_{S}^{\gamma_{S}}<\alpha_{H}^{\gamma_{S}}
\end{array}\right.
$$

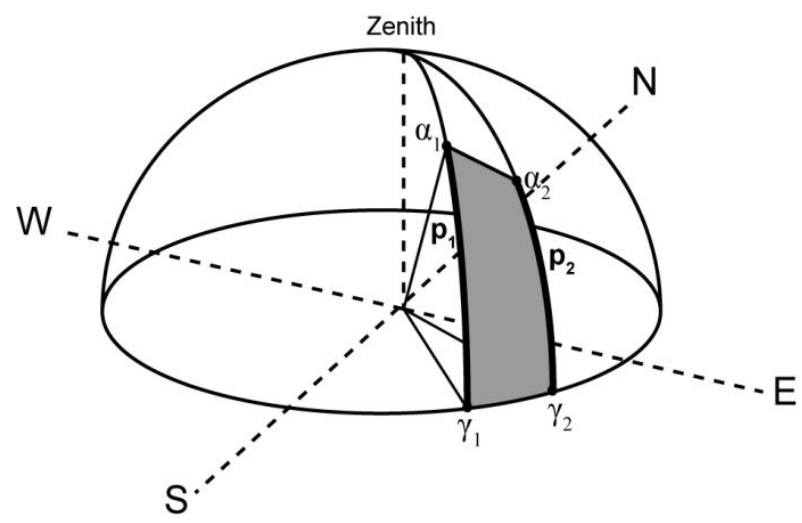

Figure 7: Projection of an object polygon on the hemisphere in order to calculate isotropic horizontal diffuse shading factor ( $\alpha$ and $\gamma$ respectively correspond to elevation angle and azimuth angle).

The isotropic horizontal diffuse shading factor $S_{d, h}$ is defined as the ratio between the horizon projection surface on the hemisphere and the total hemisphere surface. For an object polygon, as shown in figure 7 , with two ground vertices, $\left(\gamma_{1}, 0\right)$ and $\left(\gamma_{2}, 0\right)$, and two vertices $p_{1}$ and $p_{2}$ on the hemisphere that are connected by a line $\alpha(\gamma)=m \gamma+n$ with $m=\left(\alpha_{2}-\alpha_{1}\right) /\left(\gamma_{2}-\gamma_{1}\right)$ and $n=\left(\alpha_{1} \gamma_{2}-\alpha_{2} \gamma_{1}\right) /\left(\gamma_{2}-\gamma_{1}\right)$, where $\alpha$ is the elevation angle and $\gamma$ the azimuth angle, the horizontal diffuse shading factor is equal to [59]:

$$
\begin{aligned}
S_{d 1-2, h} & =\frac{\int_{\gamma_{1}}^{\gamma_{2}} \int_{0}^{m \gamma+n} \sin \alpha \cos \alpha d \alpha d \gamma}{\pi} \\
& =\left\{\begin{array}{cc}
\frac{1}{\frac{1}{2}\left(\gamma_{2}-\gamma_{1}\right) \sin ^{2} \alpha_{1}} & \text { for } m=0 \\
\frac{1}{\frac{2}{2}\left(\gamma_{2}-\gamma_{1}\right)\left(\frac{1}{2}+\frac{1}{4} \frac{\sin 2 \alpha_{1}-\sin 2 \alpha_{2}}{\alpha_{2}-\alpha_{1}}\right)} & \text { for } m \neq 0
\end{array}\right.
\end{aligned}
$$

At last, for an object with $\mathrm{n}$ vertices $\mathrm{p}$, the total isotropic horizontal diffuse shading factor is the sum over all the object polygons composing the horizon, i.e. the sum of each diffuse shading factor $S_{d i-i+1, h}$ corresponding to vertices $p_{i}$ and $p_{i+1}$ :

$$
S_{d, h}=\sum_{i=1}^{n-1} S_{d i-i+1, h}\left(p_{i}, p_{i+1}\right)
$$


Precision of the diffuse factor is directly related to the horizon azimuth resolution. For this study, we chose to compute each horizon with a 1-degree azimuth resolution, since it was a good compromise between computing time efficiency of the disaggregated solar atlas and precision of the diffuse shading factor.

After all, the global horizontal irradiance taking into account shadowing effects $G_{h, \text { shading }}(z)$ is equal to [59]:

$$
G_{h, \text { shading }}(z)=\left(1-k_{d}\right)\left(1-S_{b}\right) G_{h}(z)+k_{d}\left(1-S_{d, h}\right) G_{h}(z)
$$

As written at the beginning of part 4, the design goal of the disaggregation methodology was to improve geographic information of the solar atlas. Therefore, we deliberately didn't use any circumsolar or terrain reflectance models within the disaggregation process. On the one hand, as described in Ruiz-Arias et al. [14], terrain reflectance is very difficult to model. Ruiz-Arias et al. and Bosch et al. [15] took into account terrain reflectance within their model because of snow cover over mountains in Andalucía. In Djibouti, snow cover doesn't exist and it was consequently not justified to add isotropic reflectance and to maybe add error to the model. On the second hand, the use of a possibly unsuitable circumsolar model leads to the same problems. Since shading effects are mostly due to terrain obstruction of direct radiation, if a part of the isotropic diffuse radiation is considered like circumsolar, it is possible to finally underestimate resulting global radiation. As observed in Ruiz-Arias et al. [14] (figure 10), the superposition of a large number of modeling layers can lead originally overestimated data to be finally strongly underestimated. Therefore, as no model had ever been tested over Djibouti before this study, we preferred to implement first basic layers of the methodology in order to converge to the right estimation of solar radiation and to minimize the possible errors.

The term $G_{h, \text { shading }}(z)$ has the 1-minute time resolution of irradiance $G_{h}(z)$ and diffuse fraction $k_{d}$. By integrating it over each hour between sunrise and sunset times of all days, we got the new downscaled hourly irradiation $I_{h, \text { shading }}(z)$ over the given DEM pixel:

$$
I_{h, \text { shading }}(z)=\int_{\text {hour }} G_{h, \text { shading }}(z)
$$

At last, by computing the whole study area, we retrieved a yearly timeseries of downscaled hourly irradiation for each DEM pixel of the country, i.e. a yearly timeseries of downscaled hourly global horizontal irradiation maps. Thus, in comparison to the hourly SSI inputs, outputs are hourly solar energy 
maps, taking into account shading and elevation variability effects and having a 3 arc second spatial resolution.

\subsection{Results}

All the results presented in this section derive from computation of the year 2010.

In order to evaluate hourly irradiation estimates over a day, figure 8 presents hourly irradiation maps for the 17/12/2010. Because of the country size which would strongly reduce observation of disaggregation, figure 8 focuses over a specific reduced area, between $11.4^{\circ} \mathrm{N}-12.2^{\circ} \mathrm{N}$ latitude and $42^{\circ} \mathrm{E}-43^{\circ} \mathrm{E}$ longitude, presenting a significant topography. We chose this day, as a day where sun elevation angle was the lowest and where clearness index was the highest possible, in order to optimize observation of shadowing effects. Note that, however, some original SSI pixels, forming "square-based" patterns, strongly stand out within the different hourly maps. It is simply explained by their original type, as these pixels were either "sea" or cloudy type and already stood out before downscaling. Hourly irradiation maps, at UTC time H, correspond to global horizontal irradiation reaching the surface between $\mathrm{H}-1$ and $\mathrm{H}$. Hours 4 and 5, where clearness index is low, mainly present diffuse shading effects. Direct shading effects are localized to hours close to sunrise and sunset. A great part of the day, between 7:00 UTC and 11:00 UTC, presents only altitude correction effects. Also, some extreme lonely values, due to direct shading, still exist (around $200 \mathrm{Wh} / \mathrm{m}^{2}$ ) when solar elevation is the highest, between 8:00 UTC and 10:00 UTC, and can be explained by the sensitivity analysis presented in part 4.2.2. Nevertheless, these values are very limited and actually remain hidden. They don't really affect the whole solar cartography. 


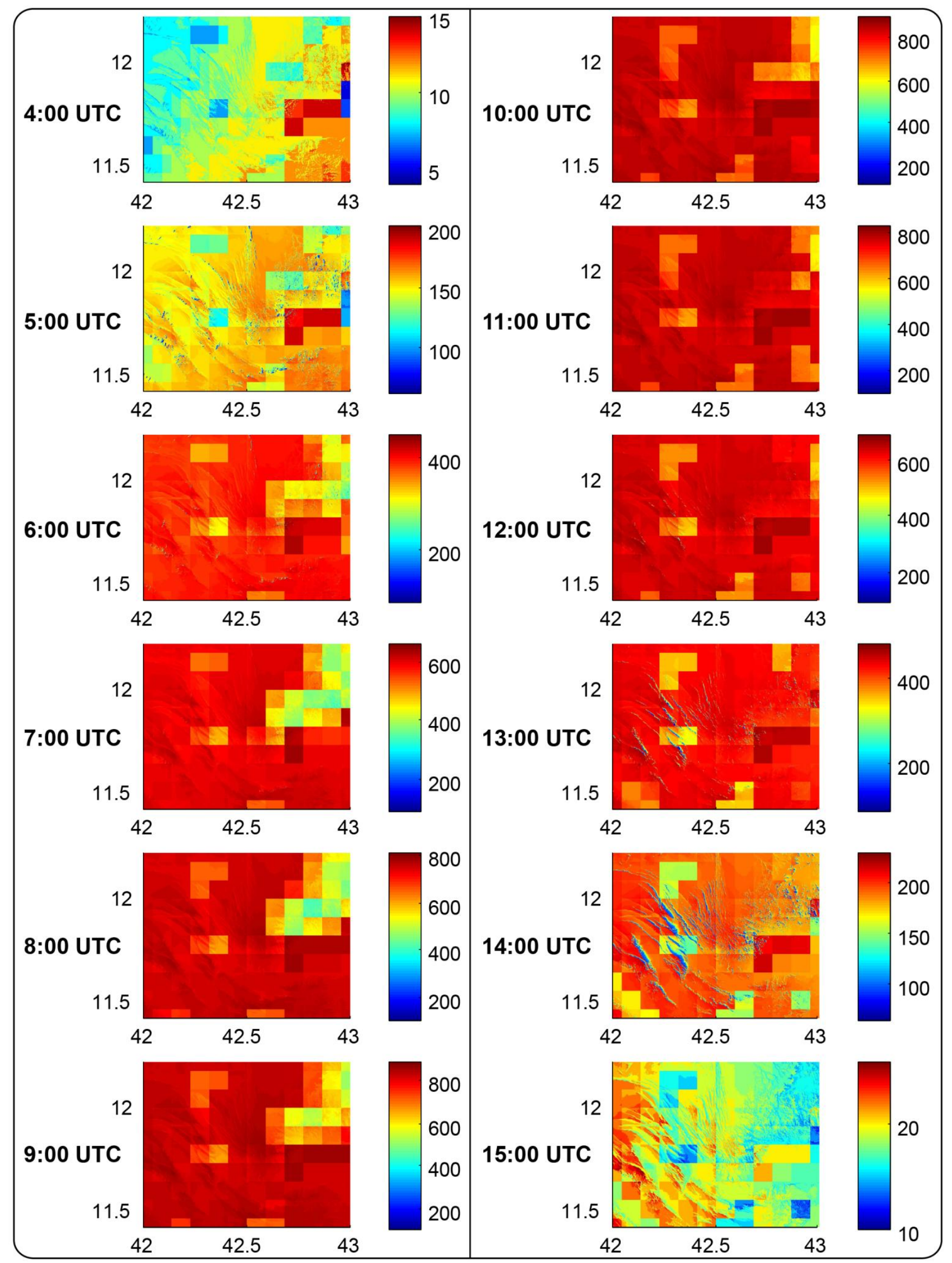

Figure 8: Hourly irradiation maps $\left(\mathrm{Wh} / \mathrm{m}^{2}\right)$ over a reduced area $\left(12.2^{\circ}-11.4^{\circ}\right.$ latitude and $42^{\circ}-43^{\circ}$ longitude $)$ for the $17 / 12 / 2010$. Each map has an hourly UTC time reference $H$ on the left, and corresponds to irradiation reaching surface between $H-1$ and $H$. 

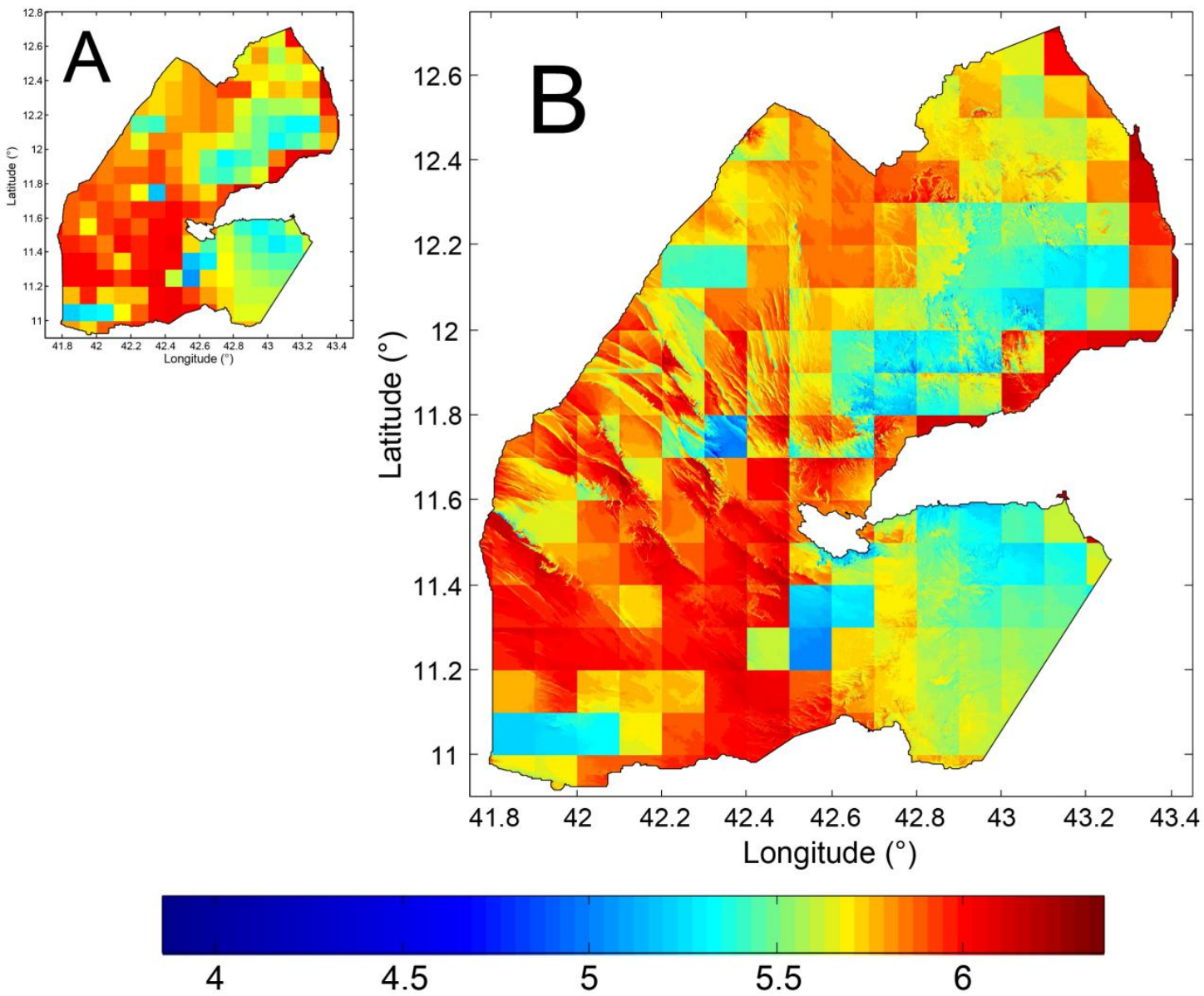

Figure 9: Yearly average daily irradiation maps $\left(\mathrm{kWh} / \mathrm{m}^{2}\right.$.day $)$ over Djibouti for the year 2010. A) Without downscaling. B) With downscaling.

Table 3: Specifications of monthly average daily global irradiation maps over Djibouti (year 2010), with and without disaggregation methodology.

Global horizontal irradiation $\left(\mathrm{kWh} / \mathrm{m}^{2}\right.$.day)

\begin{tabular}{|c|c|c|c|c|c|c|c|c|c|c|c|c|}
\hline & \multicolumn{3}{|c|}{ without disaggregation } & \multicolumn{9}{|c|}{ with disaggregation } \\
\hline & \multirow[b]{2}{*}{ range } & \multirow[b]{2}{*}{ mean } & \multirow[b]{2}{*}{ std } & \multicolumn{3}{|c|}{ Ruiz-Arias et al. } & \multicolumn{3}{|c|}{ Erbs et al. } & \multicolumn{3}{|c|}{ CLIMED 2} \\
\hline & & & & range & mean & std & range & mean & std & range & mean & std \\
\hline January & $4.27-5.90$ & 5.34 & 0.42 & $1.00-6.07$ & 5.31 & 0.44 & $1.08-6.07$ & 5.31 & 0.44 & $1.13-6.07$ & 5.31 & 0.44 \\
\hline February & $3.70-5.43$ & 4.75 & 0.49 & $2.91-5.71$ & 4.72 & 0.5 & $2.90-5.71$ & 4.72 & 0.5 & $2.90-5.71$ & 4.72 & 0.5 \\
\hline March & $5.33-6.74$ & 6.16 & 0.23 & $4.66-7.04$ & 6.13 & 0.24 & $4.64-7.04$ & 6.13 & 0.24 & $4.64-7.04$ & 6.13 & 0.24 \\
\hline April & $5.49-6.88$ & 6.31 & 0.30 & $4.63-7.24$ & 6.28 & 0.31 & $4.60-7.24$ & 6.28 & 0.31 & $4.60-7.24$ & 6.28 & 0.31 \\
\hline May & $5.34-6.94$ & 6.19 & 0.24 & $4.67-7.11$ & 6.17 & 0.26 & $4.66-7.11$ & 6.17 & 0.26 & $4.65-7.11$ & 6.17 & 0.26 \\
\hline June & 5.34-6.58 & 6.11 & 0.19 & $4.68-6.75$ & 6.08 & 0.21 & $4.68-6.75$ & 6.07 & 0.21 & $4.67-6.75$ & 6.07 & 0.21 \\
\hline July & $5.12-6.12$ & 5.76 & 0.20 & $4.37-6.39$ & 5.74 & 0.21 & $4.36-6.39$ & 5.73 & 0.21 & $4.35-6.39$ & 5.73 & 0.21 \\
\hline August & $4.90-5.94$ & 5.45 & 0.23 & $3.98-6.08$ & 5.43 & 0.25 & $3.93-6.08$ & 5.43 & 0.25 & $3.94-6.08$ & 5.43 & 0.25 \\
\hline September & $5.21-6.73$ & 5.88 & 0.28 & $4.38-6.81$ & 5.85 & 0.3 & $4.39-6.81$ & 5.84 & 0.3 & $4.39-6.81$ & 5.84 & 0.3 \\
\hline October & $5.24-6.76$ & 6.12 & 0.27 & $4.28-7.01$ & 6.1 & 0.28 & $4.31-7.01$ & 6.1 & 0.28 & $4.30-7.01$ & 6.09 & 0.28 \\
\hline November & $4.78-6.08$ & 5.60 & 0.27 & $1.57-6.24$ & 5.57 & 0.28 & $1.66-6.24$ & 5.57 & 0.28 & $1.69-6.24$ & 5.57 & 0.28 \\
\hline December & $4.31-5.57$ & 5.09 & 0.34 & $0.92-5.67$ & 5.07 & 0.36 & $1.01-5.67$ & 5.07 & 0.36 & $1.05-5.67$ & 5.07 & 0.36 \\
\hline Yearly & $5.03-6.21$ & 5.73 & 0.22 & $3.85-6.38$ & 5.71 & 0.24 & $3.87-6.38$ & 5.71 & 0.24 & $3.86-6.38$ & 5.71 & 0.24 \\
\hline
\end{tabular}

Then, in order to estimate the global horizontal irradiation potential of Djibouti, we computed yearly average and monthly average daily global irradiation maps, with and without disaggregation. Figure 9 presents both the processed yearly maps, with and without downscaling, and table 3 presents, at the same time, specifications of the monthly average daily irradiation maps with spatial range values, means and 
standard deviations (std) calculated over the country area. When disaggregation is considered, table 3 describes results for all the diffuse fraction models presented in section 3.3.

Analogous results between the 3 tested models are explained by the limited shadowing effects over the country. Firstly, as shown in figure 9.B, topography effects are localized to some regions. Then, for a day close to midwinter, figure 8 has shown that direct shading effects were restricted to hours near to sunset and sunrise. Furthermore, as clearness index was high over the year, diffuse shading effects were also limited. As Djibouti is near from equator, high sun trajectory over the year explains this specific fact. Therefore, except for the lowest monthly range values, the use of one diffuse fraction model rather than another is not significant. Considering disaggregation, methodology reduces mean and amplifies standard deviation and range very slightly. Obviously, solar irradiation all over the country quite remains the same, with or without disaggregation. Moreover, results show that disaggregation is not really monthly dependent, except for range values. The same causes producing the same effects, these results are explained by the spatial and temporal limitations of shadowing effects, and by the limitation of altitude correction, due to the high yearly clearness index.

Even so, although Djibouti is near from equator and has preferential solar conditions, some of the original SSI pixels are strongly downscaled, as shown in figure 9. Hence, depending on region features, disaggregation onto a 3 arc second spatial grid must be sparingly used. In order to avoid useless computations and, so, to obtain the best accuracy to performance ratio, such a disaggregation study must be a good balance between region location and size, solar conditions, topography characteristics and computing efficiency.

Also, we can extract some tendencies from these irradiation maps. Hence, March, April and May present the highest mean values over the country, because of a sun trajectory close to zenith. Low mean solar irradiations for July and August are explained by the presence of dust in the air, due to the "khamsin" sandstorm. At last, February is the month which seems to present the highest meteorological variability with the maximum standard deviation and the minimum mean of all the set.

Finally, with all the standard deviations less than $0.5 \mathrm{kWh} / \mathrm{m}^{2}$, and a range of mean values over the year between 4.72 and $6.28 \mathrm{kWh} / \mathrm{m}^{2}$, Djibouti presents low temporal and spatial variability of global irradiation. 
According to the final atlas, during the year 2010, mean global irradiation over the country was about 2100 $\mathrm{kWh} / \mathrm{m}^{2}$ and about $82 \%$ of the country received over $2000 \mathrm{kWh} / \mathrm{m}^{2}$. Considering complete area, the total solar irradiation reaching the country was about $4.8410^{13} \mathrm{kWh}$, which represents about 20000 times the total Djiboutian yearly energy consumption in $2005\left(\sim 2.4210^{9} \mathrm{kWh}\right)[6]$.

As an opening on possible future works, the computation of direct horizontal irradiation gave some interesting results. Hence, according to these results, mean yearly beam irradiation over the country was around $1400 \mathrm{kWh} / \mathrm{m}^{2}$, equivalent to the yearly global irradiation reaching a sunny region like Corsica. About $77 \%$ of the country received a yearly direct irradiation over $1300 \mathrm{kWh} / \mathrm{m}^{2}$. Obviously, these results are given for information and the whole computation of direct horizontal, tilted and normal irradiation will be part of a future detailed work. Furthermore, if we consider a future global off-grid electrification of Djibouti by using solar systems, we can also observe that some "solar regions" balance each other. For instance, about $6 \%$ of the country yearly receives between 1900 and $1950 \mathrm{kWh} / \mathrm{m}^{2}$ when $6 \%$ receives between 2200 and 2250 $\mathrm{kWh} / \mathrm{m}^{2}$. Hence, in order to ensure electrical network stability and avoid some electrical overload phenomena because of the intermittent nature of solar energy, possible off-grid electrification would need to rely on a detailed co variability study of solar radiation map timeseries.

\section{Conclusion}

This work has presented the first downscaled solar atlas of the Republic of Djibouti, combining a satellitebased irradiance model, developed by the EUMETSAT O\&SI SAF, and a 3 arc second DEM retrieved from CGIAR-CSI web site.

The irradiance model validation step occurred during years 2010 and 2011 by deploying 2 temporary weather stations across the country. Comparison between measurements and estimates has shown that current limits of the SSI model don't prevent results to remain acceptable, with a maximum RRMSE of about $15 \%$, for the whole hourly dataset computation. Furthermore, the present solar atlas process could be computed again in the future with a better SSI model in order to improve resolution and precision of irradiation maps. 
According to previous studies, we have used a SRTM-3 DEM to improve geographic information of solar radiation maps, by considering shadowing effects and elevation gradient. As GIS software have not been developed to downscale pre-existing irradiance maps with DEMs, we have achieved a disaggregation process by combining our own horizon model with elevation correction and irradiance splitting models. The horizon accuracy assessment study, realized in Corsica Island during the year 2010, has shown that calculated horizons could induce irradiation error over high mountainous areas, mainly because of the original DEM error. Then, through the use of specific diffuse fraction models, combined with shading factors, we have computed the new downscaled hourly irradiation. Finally, we have exposed the first global horizontal irradiation hourly maps of the country, with and without disaggregation. Because of the Djibouti's location near to the equator and a low spatial variability of the solar resource, the disaggregation method has shown that the terrain-related effects were mostly localized to specific areas. Therefore, if these maps have clearly exposed how high the solar potential all over the country was, even when disaggregation was considered, results have also revealed that the disaggregation process had to be cautiously used depending on region characteristics. The method indeed improves irradiation maps by measuring terrain influence on the radiation reaching ground but can also consumes a lot of computing time resulting in low improvements. Such a study must therefore be a good equilibrium between region location and size, solar conditions, topography characteristics and computing time in order to avoid useless calculations.

A t present time, energy supply and electrification of stand-alone populations is one of the most important challenges of Sub-Saharan developing countries. Human development of these populations is thus directly related to the electrification rate and to improve their quality of life will require an increasing of their electricity consumption by a factor of 10 or more [17]. However, the specific social and energy paradigms of these countries incite us to feature a really different energy supply pattern from the centralized power system of developed countries. As discussed in this paper, the off-grid electrification pattern, and by extension the remote energy supply pattern, is well adapted to the scattering of Sub-Saharan rural peoples throughout the territory. And, geographic dispersion and small-scale power of renewable energies make them very suitable vehicles of this new paradigm. With the $165^{\text {th }}$ rank on the HDI [18], Djibouti is a little Sub-Saharan country which perfectly symbolizes this way of life. Lack of energy supply contributes to maintain a high poverty 
level across the country, and limits human development of remote areas. Therefore, in order to include solar energy in the off-grid pattern of Djibouti, we have initiated the development of the first solar decisionmaking tool of the country. As a result, the implementation of this hourly solar irradiation atlas, presenting an acceptable original error and improved by the use of a disaggregation process, has led to irradiation maps which can be geographically used to evaluate relevance of the solar resource over rural areas of the country, and implemented within energy models in order to size stand-alone solar power systems.

\section{Acknowledgements}

This work was made possible due to the Cooperation Agreement which has been established between the Environment Science Laboratory from University of Corsica and the CERD.

We thank the "Service d'Archivage et de Traitement Météorologiques des Observations Satellitaires" (SATMOS) program, managed by Meteo-France and the "Institut des Sciences de l'Univers" (INSU), for providing SSI products reshaped onto our study area.

We are also grateful to Mr. Abdoulkhader Khaireh and the other scientists from the CERD, for helping us to install weather stations and provide radiation data.

\section{References}

[1] S. Karekezi, W. Kithyoma, Renewable energy strategies for rural Africa: is a PV-led renewable energy strategy the right approach for providing modern energy to the rural poor of sub-Saharan Africa?, Energy Policy 30 (2002) 1071-1086.

[2] S. Karekezi, Renewables in Africa-meeting the energy needs of the poor, Energy Policy 30 (2002) 1059-1069.

[3] I.M. Bugaje, Renewable energy for sustainable development in Africa: a review, Renewable and Sustainable Energy Reviews 10 (2006) 603-612. 
[4] U. Deichmann, C. Meisner, S. Murray, D. Wheeler, The economics of renewable energy expansion in rural Sub-Saharan Africa, Energy Policy 39 (2011) 215-227.

[5] T.C. Chineke, F.M. Ezike, Political will and collaboration for electric power reform through renewable energy in Africa, Energy Policy 38 (2010) 678-684.

[6] F. Ahmed Aye, Intégration des énergies renouvelables pour une politique énergétique durable à Djibouti, PhD thesis, Université de Corse, 2009.

[7] L. Diabate, P. Blanc, L. Wald, Solar radiation climate in Africa, Solar Energy 76 (2004) 733-744.

[8] F. Drake, Y. Mulugetta, Assessment of solar and wind energy resources in Ethiopia. I. Solar energy, Solar Energy 57 (1996) 205-217.

[9] R. Munzhedzi, A.B. Sebitosi, Redrawing the solar map of South Africa for photovoltaic applications, Renewable Energy 34 (2009) 165-169.

[10] A. Madhlopa, Solar radiation climate in Malawi, Solar Energy 80 (2006) 1055-1057.

[11] R. Perez, R. Seals, A. Zelenka, Comparing satellite remote sensing and ground network measurements for the production of site/time specific irradiance data, Solar Energy 60 (1997) 89-96.

[12] M. Muselli, G. Notton, J.L. Canaletti, A. Louche, Utilization of Meteosat satellite-derived radiation data for integration of autonomous photovoltaic solar energy systems in remote areas, Energy Conversion and Management 39 (1998) 1-19.

[13] B. Pillot, M. Muselli, P. Poggi, Solar atlas implementation and planning of PV system off-grid electrification in Djibouti, in: Proceedings of the 25th European Photovoltaic Solar Energy Conference and the 5th World Conference on Photovoltaic Energy Conversion, Valencia, Spain, 2010.

[14] J.A. Ruiz-Arias, T. Cebecauer, J. Tovar-Pescador, M. Š́ri, Spatial disaggregation of satellite-derived irradiance using a high-resolution digital elevation model, Solar Energy 84 (2010) 1644-1657.

[15] J.L. Bosch, F.J. Batlles, L.F. Zarzalejo, G. López, Solar resources estimation combining digital terrain models and satellite images techniques, Renewable Energy 35 (2010) 2853-2861.

[16] J.M. Huacuz, L. Gunaratne, Photovoltaics and Development, in: Handbook of Photovoltaic Science and Engineering, Wiley, England, 2003, pp. 1043-1071. 
[17] S.S. Hegedus, A. Luque, Status, trends, challenges and the bright future of solar electricity from photovoltaics, in: Handbook of Photovoltaic Science and Engineering, Wiley, England, 2003, pp. 1-43.

[18] J. Klugman, Human development report 2011 - Sustainability and equity : a better future for all, United Nations Development Programme (UNDP), New York, USA, 2011.

[19] F. Birol, World Energy Outlook 2006, International Energy Agency - Economic Analysis Division, Paris, France, 2007.

[20] United Nations, World Urbanization Prospects - Highlights, United Nations - Department of Economic and Social Affairs, New York, USA, 2008.

[21] L.L. Freris, D.G. Infield, Renewable energy in power systems, John Wiley \& Sons, Chichester, U.K., 2008.

[22] N. Wamukonya, Solar home system electrification as a viable technology option for Africa's development, Energy Policy 35 (2007) 6-14.

[23] S.D. Odeh, M. Behnia, G.L. Morrison, Performance evaluation of solar thermal electric generation systems, Energy Conversion and Management 44 (2003) 2425-2443.

[24] F. Trieb, H. Mullersteinhagen, Concentrating solar power for seawater desalination in the Middle East and North Africa, Desalination 220 (2008) 165-183.

[25] P. Viebahn, Y. Lechon, F. Trieb, The potential role of concentrated solar power (CSP) in Africa and Europe - A dynamic assessment of technology development, cost development and life cycle inventories until 2050, Energy Policy In Press, Corrected Proof (2010).

[26] M. Wentzel, A. Pouris, The development impact of solar cookers: a review of solar cooking impact research in South Africa, Energy Policy 35 (2007) 1909-1919.

[27] R. Abu-Malouh, S. Abdallah, I.M. Muslih, Design, construction and operation of spherical solar cooker with automatic sun tracking system, Energy Conversion and Management 52 (2011) 615-620.

[28] G. Guevel, Status of the OSI SAF, in: Proceedings of the 2007 EUMETSAT Meteorological Satellite Conference and the 15th Satellite Meteorology \& Oceanography Conference of the American Meteorological Society, Amsterdam, The Netherlands, 2007. 
[29] G. Guevel, The EUMETSAT Ocean and Sea Ice SAF : Overview and Status, in: SAF Training Workshop, Ocean and Sea Ice Second Workshop, Perros-Guirec, France, 2005.

[30] J. Schmetz, P. Pili, S. Tjemkes, D. Just, J. Kerkmann, S. Rota, A. Ratier, An introduction to Meteosat second generation (MSG), Bulletin of the American Meteorological Society 83 (2002) 977-992.

[31] European Organisation for the Exploitation of Meteorological Satellites, Meteosat Data Collection and Retransmission Service, Darmstadt, Germany, 2009.

[32] P. Le Borgne, G. Legendre, A. Marsouin, OSI SAF Radiative fluxes, in: SAF Training Workshop, Ocean and Sea Ice Second Workshop, Perros-Guirec, France, 2005.

[33] A. Brisson, P. Le Borgne, A. Marsouin, Development of algorithms for surface solar irradiance retrieval at O\&SI SAF low and mid latitudes, Eumetsat Ocean and Sea Ice SAF internal project team report (1999).

[34] P. Le Borgne, G. Legendre, A. Marsouin, Validation of the OSI SAF radiative fluxes over the equatorial Atlantic during AMMA experiment, in: Proceedings of the 2007 EUMETSAT Meteorological Satellite Conference and the 15th Satellite Meteorology \& Oceanography Conference of the American Meteorological Society, Amsterdam, The Netherlands, 2007.

[35] P. Le Borgne, G. Legendre, A. Marsouin, Validation of the OSI SAF radiative fluxes, in: Proceedings of the 2006 EUMETSAT Meteorological Satellite Conference, Helsinki, Finland, 2006.

[36] Ocean \& Sea Ice Satellite Application Facility, Surface Solar Irradiance Product Manual, Product User Manual (2005).

[37] C. Rogers, P. Pili, Meteosat Second Generation Level 1.5 Image, Data Format Description, European Organisation for the Exploitation of Meteorological Satellites, Darmstadt, Germany, 2001.

[38] R.T. Pinker, I. Laszlo, Modeling surface solar irradiance for satellite applications on global scale, Journal of Applied Meteorology 31 (1992) 194-211.

[39] N. Manalo-Smith, G.L. Smith, S.N. Tiwari, W.F. Staylor, Analytic forms of bidirectional reflectance functions for application to Earth radiation budget studies, Journal of Geophysical Research 103 (1998) $19733-19751$. 
[40] R. Frouin, B. Chertock, A technique for global monitoring of net solar irradiance at the ocean surface. Part 1 : Model, Journal of Applied Meteorology 31 (1992) 1056-1066.

[41] D. L. King, D. R. Myers, Silicon-photodiode pyranometers: operational characteristics, historical experiences, and new calibration procedures, in: Proceedings of the 26th IEEE Photovoltaic Specialists Conference, Anaheim, California, 1997.

[42] The EUMETSAT Satellite Application Facility on Land Surface Analysis (LSA SAF), Downwelling Surface Shortwave Flux (DSSF), Product User Manual (2011).

[43] M. Iqbal, An introduction to solar radiation, Academic Press, Toronto; New York, 1983.

[44] G. Notton, C. Cristofari, M. Muselli, P. Poggi, Calculation on an hourly basis of solar diffuse irradiations from global data for horizontal surfaces in Ajaccio, Energy Conversion and Management 45 (2004) 2849-2866.

[45] I. Moradi, R. Mueller, B. Alijani, G.A. Kamali, Evaluation of the Heliosat-II method using daily irradiation data for four stations in Iran, Solar Energy 83 (2009) 150-156.

[46] J.A. Ruiz-Arias, J. Tovar-Pescador, D. Pozo-Vazquez, H. Alsamamra, A comparative analysis of DEM-based models to estimate the solar radiation in mountainous terrain, International Journal of Geographical Information Science 23 (2009) 1049-1076.

[47] T.G. Farr, P.A. Rosen, E. Caro, R. Crippen, R. Duren, S. Hensley, M. Kobrick, M. Paller, E. Rodriguez, L. Roth, others, The shuttle radar topography mission, Reviews of Geophysics 45 (2007).

[48] B. Rabus, M. Eineder, A. Roth, R. Bamler, The shuttle radar topography mission--a new class of digital elevation models acquired by spaceborne radar, ISPRS Journal of Photogrammetry and Remote Sensing 57 (2003) 241-262.

[49] A. Jarvis, J. Rubiano, A. Nelson, A. Farrow, M. Mulligan, Practical use of SRTM data in the tropics: comparisons with digital elevation models generated from cartographic data, Working document 198 (2004) 32.

[50] A. Jarvis, H.I. Reuter, A. Nelson, E. Guevara, Hole-filled seamless SRTM data V4, International Centre for Tropical Agriculture (CIAT), available from http://srtm.csi.cgiar.org (last time accessed January, 2010). 
[51] J. Hofierka, T. Huld, T. Cebecauer, M. Suri, Open Source Solar Radiation Tools for Environmental and Renewable Energy Applications, in: Proceedings of the International Symposium on Environmental Software Systems, Prague, Czech Republic, 2007.

[52] M. Š́ri, J. Hofierka, A New GIS-based Solar Radiation Model and Its Application to Photovoltaic Assessments, Transactions in GIS 8 (2004) 175-190.

[53] G.C. Miliaresis, C.V.E. Paraschou, Vertical accuracy of the SRTM DTED level 1 of Crete, International Journal of Applied Earth Observation and Geoinformation 7 (2005) 49-59.

[54] Y. Gorokhovich, A. Voustianiouk, Accuracy assessment of the processed SRTM-based elevation data by CGIAR using field data from USA and Thailand and its relation to the terrain characteristics, Remote Sensing of Environment 104 (2006) 409-415.

[55] M.A. Wahab, M. El-Metwally, R. Hassan, M. Lefevre, A. Oumbe, L. Wald, Assessing surface solar irradiance and its long-term variations in the northern Africa desert climate using Meteosat images, International Journal of Remote Sensing 31 (2010) 261-280.

[56] J.A. Ruiz-Arias, H. Alsamamra, J. Tovar-Pescador, D. Pozo-Vázquez, Proposal of a regressive model for the hourly diffuse solar radiation under all sky conditions, Energy Conversion and Management 51 (2010) 881-893.

[57] D.G. Erbs, S.A. Klein, J.A. Duffie, Estimation of the diffuse radiation fraction for hourly, daily and monthly-average global radiation, Solar Energy 28 (1982) 293 - 302.

[58] A. De Miguel, J. Bilbao, R. Aguiar, H. Kambezidis, E. Negro, Diffuse solar irradiation model evaluation in the north Mediterranean belt area, Solar Energy 70 (2001) 143-153.

[59] V. Quaschning, R. Hanitsch, Irradiance calculation on shaded surfaces, Solar Energy 62 (1998) 369375. 